\title{
Twentieth Century Winter Changes in Southern Hemisphere Synoptic Weather Modes
}

\author{
Jorgen S. Frederiksen ${ }^{1}$ and Carsten S. Frederiksen ${ }^{2}$ \\ ${ }^{1}$ Centre for Australian Weather and Climate Research, CSIRO Marine and Atmospheric Research, Aspendale, 3195 VIC, Australia \\ ${ }^{2}$ Centre for Australian Weather and Climate Research, Bureau of Meteorology, Docklands, 3008 VIC, Australia
}

Correspondence should be addressed to Jorgen S. Frederiksen, jorgen.frederiksen@csiro.au

Received 22 January 2011; Revised 21 June 2011; Accepted 29 June 2011

Academic Editor: Klaus Dethloff

Copyright ( 2011 J. S. Frederiksen and C. S. Frederiksen. This is an open access article distributed under the Creative Commons Attribution License, which permits unrestricted use, distribution, and reproduction in any medium, provided the original work is properly cited.

\begin{abstract}
During the last sixty years, there have been large changes in the southern hemisphere winter circulation and reductions in rainfall particularly in the southern Australian region. Here we examine the corresponding changes in dynamical modes of variability ranging from storm tracks, onset-of-blocking modes, northwest cloud-band disturbances, Antarctic low-frequency modes, intraseasonal oscillations, and African easterly waves. Our study is performed using a global two-level primitive equation instability-model with reanalyzed observed July three-dimensional basic states for the periods 1949-1968, 1975-1994, and 19972006. We relate the reduction in the winter rainfall in the southwest of Western Australia since the mid-1970s and in south-eastern Australia since the mid-1990s to changes in growth rate and structures of leading storm track and blocking modes. We find that cyclogenesis and onset-of-blocking modes growing on the subtropical jet have significantly reduced growth rates in the latter periods. On the other hand there is a significant increase in the growth rate of northwest cloud-band modes and intraseasonal oscillation disturbances that cross Australia and are shown to be related to recent positive trends in winter rainfall over northwest Western Australia and central Australia, in general. The implications of our findings are discussed.
\end{abstract}

\section{Introduction}

Major shifts in the structure of the large-scale circulation of both the northern and southern hemispheres have occurred during the last sixty years or so (see $[1,2]$, for overview). A number of studies [3-16], have also shown that, since the early to mid-1970s, there has been a dramatic and continuing reduction, as well as negative trend, in the winter rainfall over southern Australia with very large reductions (approximately 20\%) occurring first in the southwest of Western Australia (SWWA). More recently, during the last decade or so, there have also been large rainfall reductions in south-eastern Australia [8-11, 17-21].

As reviewed by Frederiksen [22], normal mode instability theory has been widely used to understand the dynamics of weather systems [23] and their predictability [24]. Of course nonlinear effects will cause modifications of the disturbances as they increase [25]. Nevertheless, normal modes of climatological basic states and finite-time normal modes of time evolving basic states capture many of the important properties of atmospheric disturbances and their predictability [22].

Recently, J. S. Frederiksen and C. S. Frederiksen $[1,2]$ investigated whether the impact of the dramatic changes in the mean July climate of the atmospheric circulation and thermal structure, for the periods 1949-1968 and 1975-1994, on changes in the southern hemisphere (SH) storm track modes could explain the dramatic decrease in rainfall between these periods. A significant difference between the two periods was a reduction of $17 \%$ in the peak strength of the SH subtropical jetstream over the southern Indian Ocean upstream of Australia. They found also that there was a hemisphere-wide reduction in the upper-level zonal winds and vertical wind shear near 30S, and increases in a hemispheric band near 50S. There was also a significant warming of the $\mathrm{SH}$ atmosphere south of $30 \mathrm{~S}$ and a reduced equator-to-pole temperature gradient particularly in the eastern hemisphere. These changes were shown to 


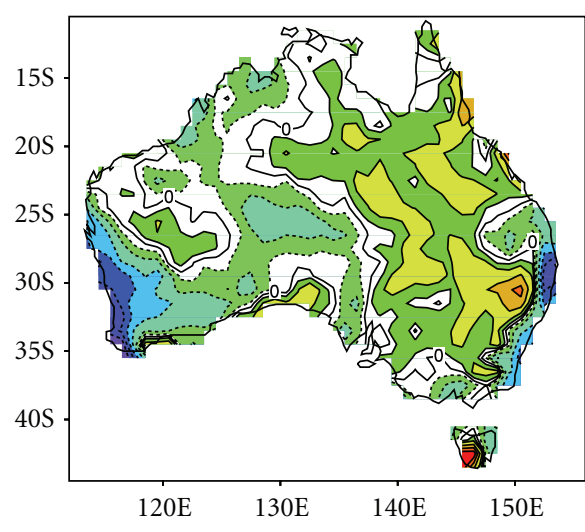

(a)

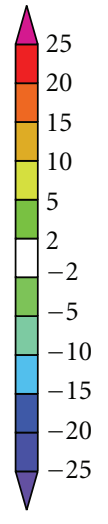

.

政

Figure 1: Observed July Australian rainfall differences (1975-94) minus (1949-68) (mm/month) (a) and 1950 to 1999 trend in July Australian rainfall (mm/month/year) (b).

be associated with about a 33\% reduction in growth rates of leading July SH storm track modes, or weather systems, crossing Australia, resulting in a reduction in the intensity of storm formation and the southward deflection of some storms. This has been the primary cause of the rainfall reduction over southwest Western Australia and southern Australia, in general, since 1975.

Frederiksen et al. [9] used the Phillips criterion [26] as a diagnostic for evaluating the ability of climate models to capture these changes in the growth rates of storm track modes and the preferred location of storm development. Over the last sixty years, there have been large reductions in the Phillips criterion, or baroclinic instability, near $30 \mathrm{~S}$ in a hemispheric band consistent with the reductions in the growth rate of storm development in the Australian region. Frederiksen et al. $[10,11]$ showed that there was a close relationship between the reduction in the Phillips criterion and reductions in winter rainfall during the twentieth century. They also showed, using climate models that were able to reproduce observed changes in the Phillips criterion, that the impact of further increases in anthropogenic $\mathrm{CO}_{2}$ concentrations can lead to further large reductions and significant negative trends in baroclinic instability, by the end of the 21st century, resulting in further reductions in the growth rates of the storm track modes.

In this paper, we extend the studies of J. S. Frederiksen and C. S. Frederiksen [1, 2] and Frederiksen et al. [9] and examine other important dynamical modes of variability including onset-of-blocking modes, northwest cloud-band disturbances, Antarctic low-frequency modes, intraseasonal oscillations, and African easterly waves. As in these studies, we look at the leading eigenmodes of the linearized atmospheric equations of motion using the primitive equation model of J. S. Frederiksen and C. S. Frederiksen $[2,27]$. We focus on the month of July for three periods 1949-1968, 1975-1994, and 1997-2006, with the aim to see whether the properties of the leading dynamical modes can explain some of the observed changes and trends in Australian rainfall (Figures 1(a) and 1(b)) derived from the Australian

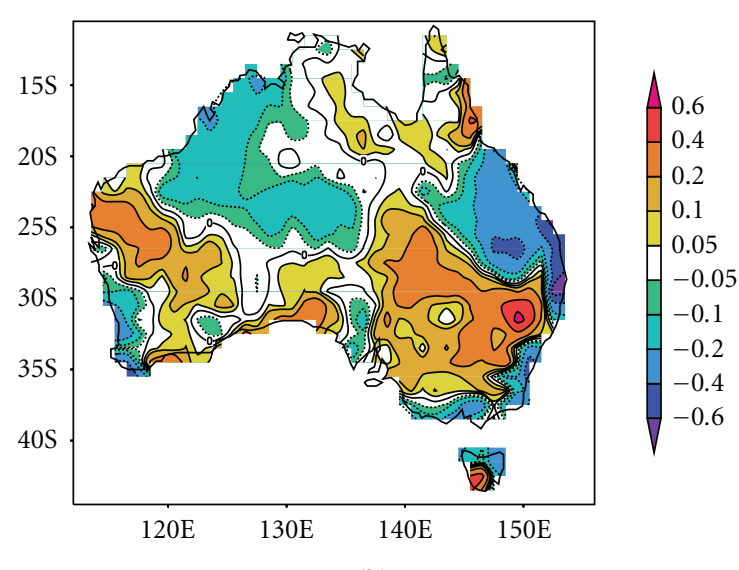

(b)
Bureau of Meteorological National Climate Centre mean gridded rainfall dataset [28]. Figure 1(a) shows the difference in rainfall between the periods 1975-1994 and 1949-1968 with large reductions over SWWA and eastern and southeastern Australia of around 20\%,30\%, and 10\%, respectively. The linear trend in rainfall, over the period 1950-1999, is shown in Figure 1(b). Consistent with Figure 1(a), this shows substantial negative trends over SWWA and eastern and south-eastern Australia and substantial positive trends over northwest Western Australia and over parts of central Australia.

The plan of this work is as follows. In Section 2, we describe briefly the details of the instability model and some of the climatological fields that constitute the basic states used in the analysis. In Section 3, we discuss the properties of the instability modes in each of the three periods and discuss some of the more significant changes. In Sections 4 to 8, we discuss the five categories of $\mathrm{SH}$ dynamical modes that have changed most dramatically over the last sixty or so years, and in Section 9 we examine the sensitivity of our results to the choice of dissipation. Our conclusions are in Section 10.

\section{Model Details and Basic States}

The transient instabilities analyzed in this study have been obtained using the two-level linearized primitive equation model that was developed and applied in a series of studies by J. S. Frederiksen and C. S. Frederiksen [27, 29, 30] and by Frederiksen [31]. The current version of the model includes a generalized Kuo-type heating parameterization that incorporates closures for both convection and evaporation-wind feedback, as outlined in our appendix. We use the values of the model parameters specified in Appendix A that are the same as the standard values used by J. S. Frederiksen and C. S. Frederiksen $[1,2]$ except in Section 9 where the effect of the choice of dissipation is examined.

For the results presented in this paper, the source of the observed fields is the National Centres for Environmental Prediction/National Center for Atmospheric Research 


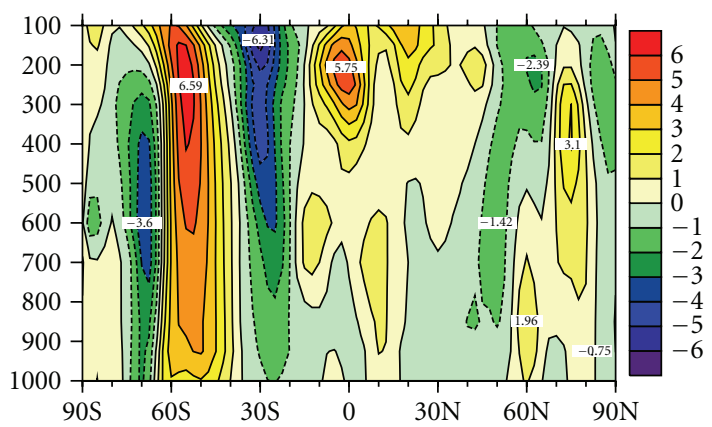

(a)

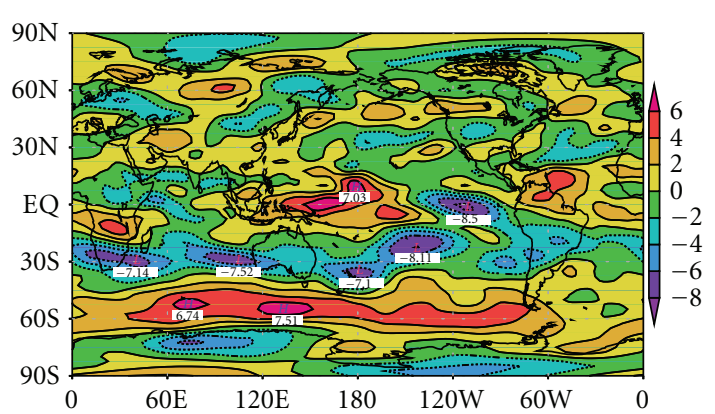

(b)

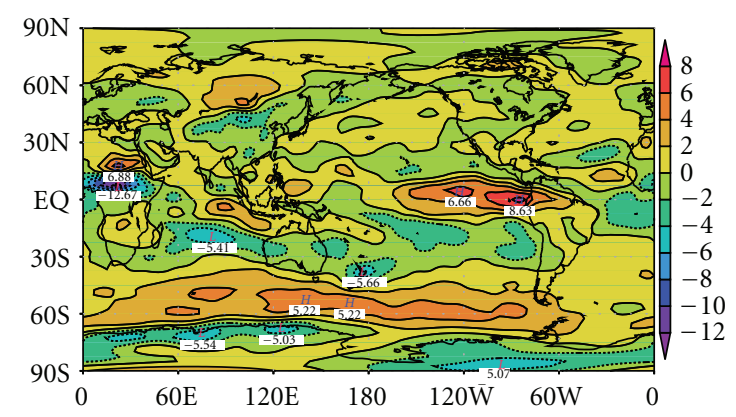

(c)

FIGURE 2: Difference between (1997-2006) and (1949-68) basic states of vertical cross-section of July zonal wind (ms $\left.{ }^{-1}\right)$ averaged between $110^{\circ}$ and $160^{\circ} \mathrm{E}$ as a function of latitude and pressure (in hPa) (a), $300 \mathrm{hPa}$ July zonal wind ( $\mathrm{ms}^{-1}$ ) (b) and $700 \mathrm{hPa}$ July zonal wind (ms ${ }^{-1}$ ) (c).

(NCEP/NCAR) reanalysis project [32]. Detailed comparisons of studies of transient modes with NCEP/NCAR and ERA40 basic states were made in J. S. Frederiksen and C. S. Frederiksen [2], and it was found that for the same periods of time the structures and growth rates of the modes considered were generally very similar.

We focus on the global Southern Hemisphere ( $\mathrm{SH})$ mean July climate fields for the periods 1949-68 and 1975-94, as in J. S. Frederiksen and C. S. Frederiksen [2], and also consider the more recent period 1997-2006. We recall that between the periods 1948-68 and 1975-94 there is a very significant reduction of $17 \%$ in the peak strength of the $\mathrm{SH}$ subtropical jet stream (Figure 1 of [2]). A similar reduction occuring between 1948-68 and 1997-2006 is seen in Figure 2(a) which shows the height (in pressure units) and latitudinal cross-section of the zonal wind, averaged over $110^{\circ} \mathrm{E}-160^{\circ} \mathrm{E}$ longitude. The latitudinal and longitudinal changes between the latter periods at $300 \mathrm{hPa}$ are also shown in Figure 2(b). There we note the reduction in the subtropical jet strength near $30^{\circ} \mathrm{S}$ is largely zonally symmetric and is accompanied by a corresponding increase in the zonal wind near $50^{\circ} \mathrm{S}$. These changes also extend to lower levels with reduced magnitudes as shown for $700 \mathrm{hPa}$ in Figure 2(c).

The changes in the zonal wind shown in Figure 2 are associated with changes in the thermal structure of the SH atmosphere. By 1997-2006 there has been a significant warming south of $30^{\circ} \mathrm{S}$, as shown by the $500 \mathrm{hPa}$ temperature difference between 1997-2006 and 1949-69 in Figure 3(a). This has reduced the equator-to-high-latitude temperature gradient across the whole Southern Hemisphere. More over, the difference in the $500 \mathrm{hPa}$ geopotential height between the two periods (Figure 3(b)) is associated with a change in the strength of the Antarctic Oscillation or southern hemisphere annular mode (SAM), [33-36]. The changes in SAM extend to the surface pressure as shown in Figure 3(c). These largescale global changes would be expected to have a significant effect on the stability of the Southern Hemisphere circulation and hence on the nature of the Southern Hemisphere storms and other modes of weather variability.

The flow fields for the basic states that we focus on in this paper are the monthly averaged July global fields for the periods 1949-68, 1975-94, and 1997-2006 from the NCEP/NCAR reanalyses. We use global $300 \mathrm{hPa}$ and $700-\mathrm{hPa}$ fields as representative of the upper and lower levels, respectively and the fields of streamfunction, velocity potential, and potential temperature are represented as rhomboidal wavenumber $R=15$ spectral fields as described in J. S. Frederiksen and C. S. Frederiksen [29].

\section{Calculation of Weather Modes}

The synoptic weather modes and lower-frequency disturbances for the 1949-68, 1975-94, and 1997-2006 basic states described in Section 2 have been calculated using the methods described in Appendix A. As in our previous studies, a wide variety of modal disturbances that can be related to many aspects of atmospheric dynamics have been obtained. Here we consider some of the faster growing modes that show significant differences in growth rates between the three time periods. As noted in J. S. Frederiksen and 


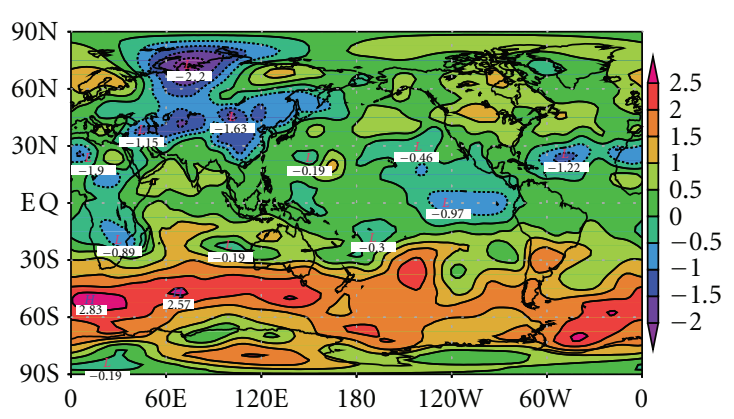

(a)

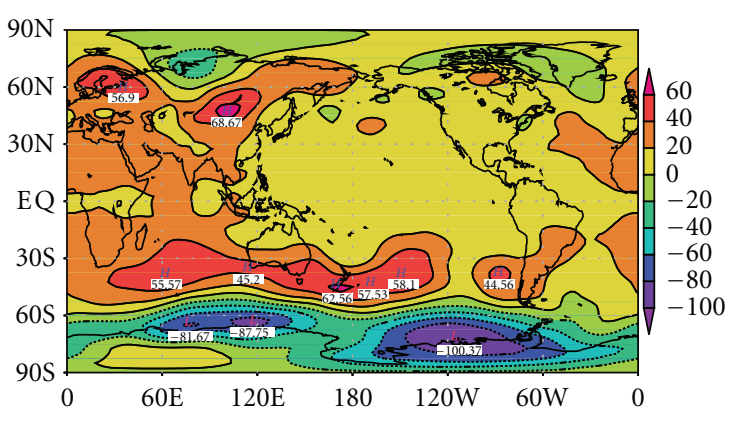

(b)

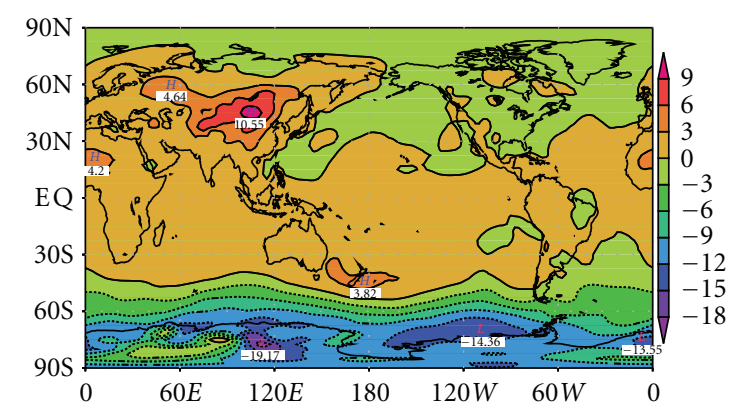

(c)

Figure 3: Difference between (1997-2006) and (1949-68) basic states of vertical cross-section of July 500 hPa temperature (K) (a), 500 hPa geopotential height $(\mathrm{m})(\mathrm{b})$, and sea-level pressure $(\mathrm{hPa})(\mathrm{c})$.

C. S. Frederiksen [2], Southern Hemisphere July storm track modes have significantly smaller growth rates during 1975-94 compared with 1949-68. We find that growth rates of leading Southern Hemisphere July storm track modes are also reduced in 1997-2006 compared with 1949-68. A major focus of this paper is to examine growth rate changes in onset-of-blocking modes, Antarctic modes, northwest cloud band modes, and intraseasonal oscillation modes between these three periods. Here the modes are ordered by decreasing growth rate, and the mode number specifies that order.

Table 1 gives the mode number, period, and growth rates of modes of particular interest for the 1949-68 and 1975-94 basic states. Also shown are the mode types and the largest pattern correlations between corresponding modes for the two basic states. Corresponding results for the 1949-68 and 1997-2006 basic states are shown in Table 2. The modes have been ordered in terms of classes with generally increasing periods followed by the purely tropical African easterly wave modes. There are additional modes whose properties are not summarized in the Tables. These modes include northern hemisphere modes, which will not be considered here, and subdominant southern hemisphere modes, many of which are storm track modes, with properties similar to the leading modes or that do not affect the Australian region. In these two tables, the pattern correlations shown are the maximum over the phases of the modes and the averages taken over the five model fields $\psi, \tau, \chi, \theta$, and $\sigma$. The pattern correlations of the perturbation fields are calculated as described in Appendix C of Frederiksen and Bell [37]. For a good fit, the pattern correlations as calculated require that both the real and imaginary parts of the two modes of interest are similar; this ensures that two travelling modes are similar throughout their evolution. It is, however, a more stringent criterion than just calculating pattern correlations between the same type of fields at just one corresponding phase, and therefore our correlations may tend to be smaller.

The leading mode for the 1949-68 basic state is a SH cyclogenesis mode with large pattern correlation (approximately 0.9) with mode 9 for the 1975-94 basic state (Table 1) and with mode 12 for the 1997-2006 basic state (Table 2). For the later periods the growth rates of the $\mathrm{SH}$ cyclogenesis modes are reduced by $33 \%$ (Table 1 ) and $37 \%$ (Table 2), respectively. Thus the growth rate reduction has continued to the most recent period. As noted in J. S. Frederiksen and C. S. Frederiksen [2], on average the 10 leading Southern Hemisphere cyclogenesis modes for 1975-94, most of which cross Australia, have growth rates that are $32 \%$ smaller than for the corresponding modes for 1949-68. This property of leading $\mathrm{SH}$ cyclogenesis modes crossing Australia to have reduced growth rates of approximately $30 \%$ continues to the most recent period of 1997-2006.

From Tables 1 and 2 we note that there is little systematic change in the growth rates of leading Antarctic modes in the latter periods 1975-94 and 1997-2006 compared with the early period. For the midlatitude $\mathrm{SH}$ onset-of-blocking modes, there is considerable reduction in growth rates in the latter periods, and pattern correlations between mode 30 for 1949-68 and those for the latter periods are less than the 0.7578 (not shown) between mode 21 for 1975-94 and mode 26 for 1997-2006. The growth rates of northwest cloud-band and intraseasonal oscillation modes increase considerably 
TABLE 1: Periods $T_{r}^{d}$ and growth rates $\omega_{i}^{d}$ of selected modes for the 1949-68 NCEP/NCAR basic state with standard parameterizations $\left(K^{\prime d}=2.338 \times 10^{16} \mathrm{~m}^{4} \mathrm{~s}^{-1}, Q_{F}^{d}=1500 \mathrm{~K}, C_{F}^{d}=5 \times 10^{-4} \mathrm{~K} \mathrm{~m}^{-1}\right)$, their mode number, and class of mode. Also shown are the largest pattern correlations $A_{c}$ between a given mode and the modes for the 1975-94 NCEP/NCAR basic state with standard parameterizations and the 1975-94 mode for which the pattern correlation is largest as well as the change in the growth rate $\Delta \omega_{i}^{d}$.

\begin{tabular}{|c|c|c|c|c|c|c|c|c|}
\hline Class & $\begin{array}{c}\text { Mode } \\
1949-68\end{array}$ & $\begin{array}{c}T_{r}^{d} \\
\text { (days) }\end{array}$ & $\begin{array}{c}\omega_{i}^{d} \\
\left(\text { day }^{-1}\right)\end{array}$ & $\begin{array}{c}T_{r}^{d} \\
\text { (days) }\end{array}$ & $\begin{array}{c}\omega_{i}^{d} \\
\left(\text { day }^{-1}\right)\end{array}$ & $A_{c}$ & $\begin{array}{c}\text { Mode } \\
1975-94\end{array}$ & $\Delta \omega_{i}^{d}$ \\
\hline SH cyclogenesis & 1 & 1.20 & 0.4250 & 1.30 & 0.2824 & 0.9148 & 9 & $-33.5 \%$ \\
\hline ML blocking & 30 & 6.11 & 0.2566 & 6.25 & 0.2279 & 0.4597 & 21 & $-11.2 \%$ \\
\hline HL blocking & 8 & 7.40 & 0.3495 & 8.02 & 0.3317 & 0.8342 & 4 & $-5.1 \%$ \\
\hline HL blocking & 11 & 5.22 & 0.3184 & 5.08 & 0.3101 & 0.8468 & 6 & $-2.6 \%$ \\
\hline NWCB & 43 & 8.01 & 0.2100 & 8.19 & 0.2624 & 0.8036 & 12 & $+24.9 \%$ \\
\hline Antarctic & 6 & 13.08 & 0.3624 & 17.48 & 0.3606 & 0.9416 & 3 & $-0.5 \%$ \\
\hline Antarctic & 26 & 52.1 & 0.2746 & 121.3 & 0.2700 & 0.8542 & 11 & $-1.7 \%$ \\
\hline ISO & 57 & 59.0 & 0.1444 & 41.85 & 0.1858 & 0.8506 & 35 & $+28.7 \%$ \\
\hline African EW & 22 & 4.14 & 0.2881 & 3.83 & 0.3071 & 0.7959 & 7 & $+6.6 \%$ \\
\hline
\end{tabular}

TABLE 2: Periods $T_{r}^{d}$ and growth rates $\omega_{i}^{d}$ of selected modes for the 1949-68 NCEP/NCAR basic state with standard parameterizations $\left(K^{\prime d}=2.338 \times 10^{16} \mathrm{~m}^{4} \mathrm{~s}^{-1}, Q_{F}^{d}=1500 \mathrm{~K}, C_{F}^{d}=5 \times 10^{-4} \mathrm{~K} \mathrm{~m}^{-1}\right)$, their mode number, and class of mode. Also shown are the largest pattern correlations $A_{c}$ between a given mode and the modes for the 1997-2006 NCEP/NCAR basic state with standard parameterizations and the 1997-2006 mode for which the pattern correlation is largest as well as the change in the growth rate $\Delta \omega_{i}^{d}$.

\begin{tabular}{|c|c|c|c|c|c|c|c|c|}
\hline Class & $\begin{array}{c}\text { Mode } \\
1949-68\end{array}$ & $\begin{array}{c}T_{r}^{d} \\
\text { (days) }\end{array}$ & $\begin{array}{c}\omega_{i}^{d} \\
\left(\text { day }^{-1}\right)\end{array}$ & $\begin{array}{c}T_{r}^{d} \\
\text { (days) }\end{array}$ & $\begin{array}{c}\omega_{i}^{d} \\
\left(\text { day }^{-1}\right)\end{array}$ & $A_{c}$ & $\begin{array}{c}\text { Mode } \\
1997-2006\end{array}$ & $\Delta \omega_{i}^{d}$ \\
\hline SH cyclogenesis & 1 & 1.20 & 0.4250 & 1.33 & 0.2663 & 0.8960 & 12 & $-37.3 \%$ \\
\hline ML blocking & 30 & 6.11 & 0.2566 & 6.27 & 0.2074 & 0.6399 & 26 & $-19.2 \%$ \\
\hline HL blocking & 8 & 7.40 & 0.3495 & 8.01 & 0.3500 & 0.7644 & 5 & $+0.1 \%$ \\
\hline HL blocking & 11 & 5.22 & 0.3184 & 4.99 & 0.3060 & 0.8028 & 6 & $-3.9 \%$ \\
\hline NWCB & 43 & 8.01 & 0.2100 & 7.97 & 0.3054 & 0.6374 & 7 & $+45.4 \%$ \\
\hline Antarctic & 6 & 13.08 & 0.3624 & 20.0 & 0.3810 & 0.9071 & 3 & $+4.9 \%$ \\
\hline Antarctic & 26 & 52.1 & 0.2746 & $\infty$ & 0.2850 & 0.6475 & 10 & $+3.8 \%$ \\
\hline ISO & 57 & 59.0 & 0.1444 & 25.4 & 0.1886 & 0.5744 & 33 & $+30.6 \%$ \\
\hline African EW & 22 & 4.14 & 0.2881 & 3.86 & 0.3035 & 0.7638 & 8 & $+5.3 \%$ \\
\hline
\end{tabular}

in the latter time intervals. For the modes with both high latitude and midlatitude multipole structures the changes in growth rates are small while the African easterly waves show moderate increases in growth rate during the latter time periods. All the modes considered are eastward propagating apart from the African easterly waves.

In the following sections, we examine the structures of the main classes of Southern Hemisphere modes in Tables 1 and 2 during the three periods of interest and relate them, in particular, to the observed changes in Australian rainfall (Figure 1).

\section{Southern Hemisphere Storm Track Modes}

4.1. Growth Rate and Periods. The leading Southern Hemisphere storm track modes $[38,39]$ for the time intervals 1949-68, 1975-94, and 1997-2006 are modes 1, 9, and 12. As shown in Tables 1 and 2, they all have periods of 1.3 days but growth rates of $0.423 \mathrm{day}^{-1}, 0.282 \mathrm{day}^{-1}$, and $0.266 \mathrm{day}^{-1}$ and pattern correlations with mode 1 for 1949-68 of 1.0, 0.915, and 0.896 , respectively. This corresponds to reductions in growth rates of 33.5 per cent and 37.3 per cent during 197594 and 1997-2006, respectively.
4.2. Structures of Storm Track Modes. Figure 4 shows the upper level streamfunction at a particular instance, its random-phase ensemble average (RPEA), the upper level divergence, and its RPEA for mode 12 for the 1997-2006 basic state, which is the fastest growing storm track mode crossing Australia. The RPEA of these fields is defined as in Equation (2.7) of Frederiksen [40]. The RPEA of a disturbance field is essentially the amplitude envelope within which the disturbance propagates with changing time or phase and determines in this case the structure of the storm track. Mode 12 for the 1997-2006 basic state is very similar to mode 1 for 1949-68 and mode 9 for 1975-94, as expected from their high pattern correlations. Like mode 1 for 1949-68 and mode 9 for 1975-94, the disturbance has a wavenumber of around 12 in the regions of large amplitude over southern Australia and consists of a series of eastward-propagating troughs (cool colours) and ridges (warm colours). As the troughs and ridges move eastward they amplify to reach a maximum in preferred regions of large RPEA amplitude. In Figures 4(b) and 4(d), the amplitude variations of the storm mode are more evident with both the streamfunction and divergence fields having largest amplitude focused over 


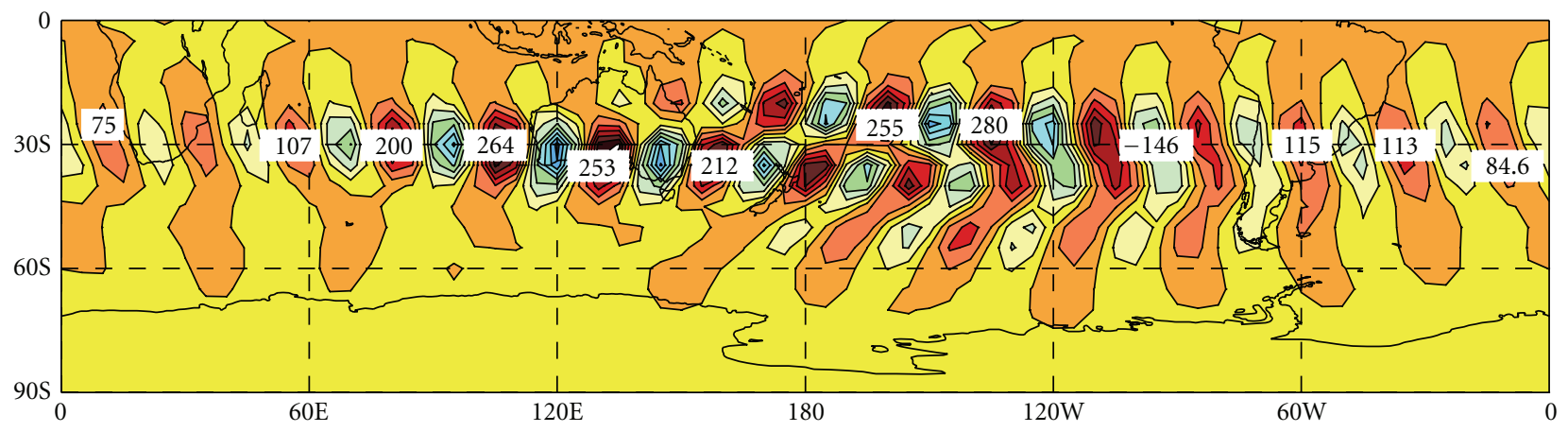

(a)

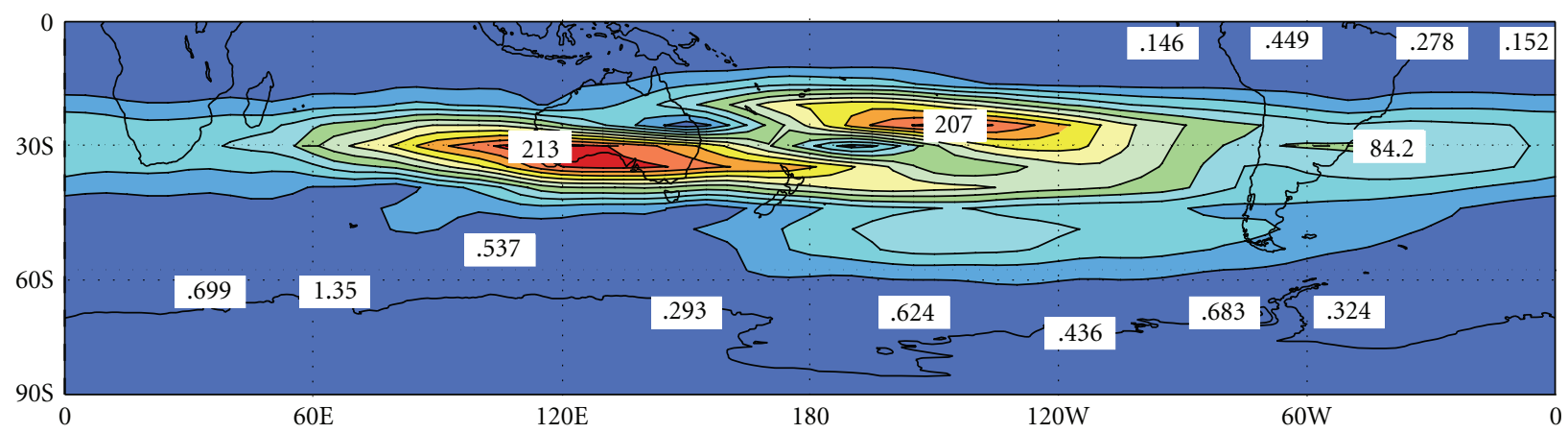

(b)

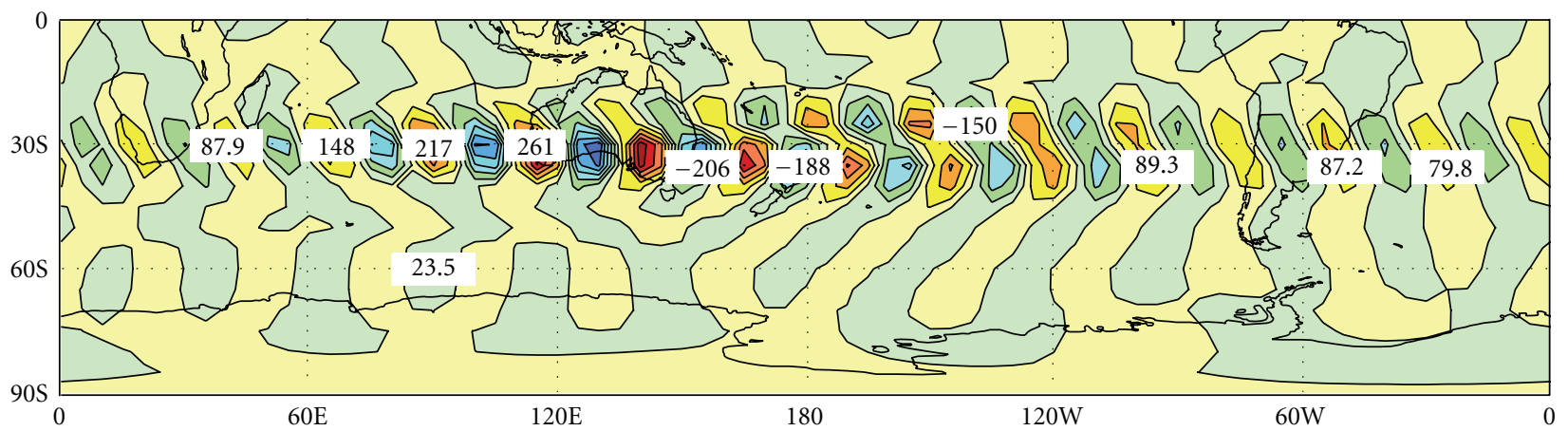

(c)

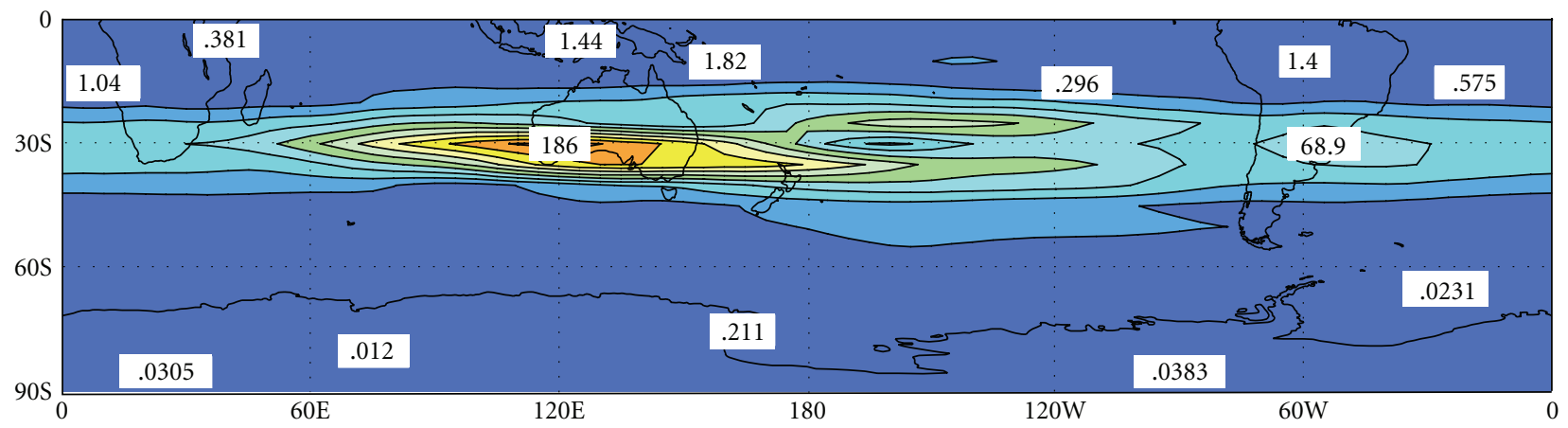

(d)

FIgURE 4: Shown in arbitrary units are the upper-level streamfunction (a), the RPEA of the upper-level streamfunction (b), the upperlevel divergence (c), and the RPEA of the upper-level divergence (d) for mode 12, the fastest growing SH storm track mode for the July 1997-2006 basic state. 


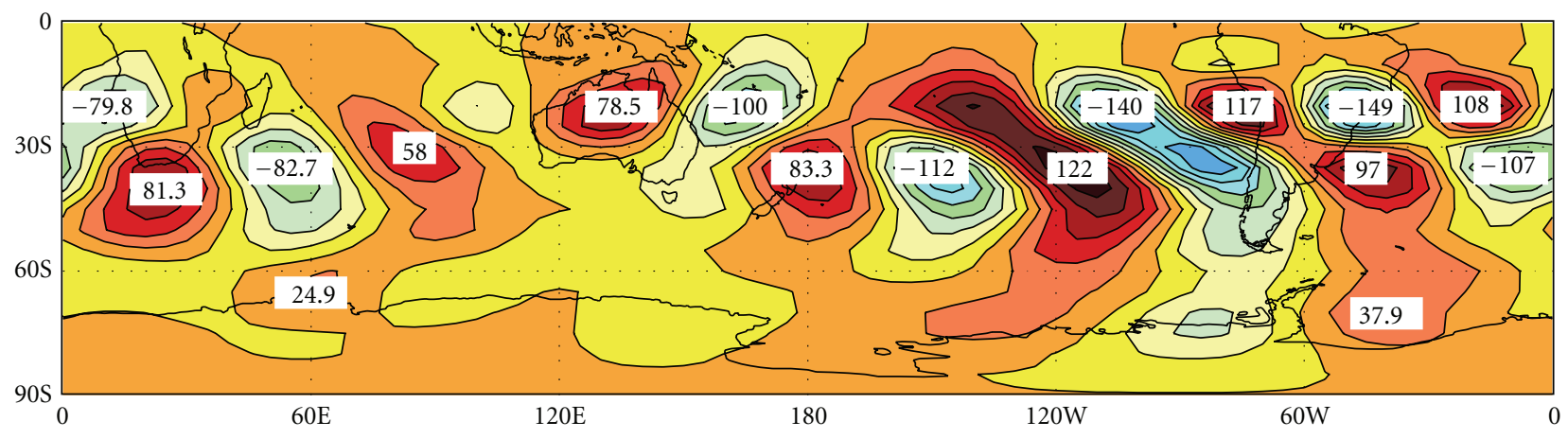

FIGURE 5: As in Figure 4(a) but for the SH midlatitude onset-of-blocking mode, mode 26, for the July 1997-2006 basic state.

south-western Australia and secondary maxima over the central Southern Pacific Ocean. We note that precipitation is essentially determined by the lower level vertical velocity in pressure coordinates, and in our model this is proportional to the magnitude of the upper level divergence. Thus, the pattern of RPEA divergence in Figure 4(c) is also the expected pattern of rainfall associated with this mode, and as we have noted above, the maximum is focused over southern Australia. Thus the significant reduction in growth rates of storm track modes in the latter two time intervals (1975-94 and 1997-2006) has been consistent with the reduction in rainfall (Figure 1) over southern Australia and, in particular southwest Western Australia, since the 1970s.

Mode 12, shown in Figure 4, is the fastest growing of a class of cyclogenesis modes with zonal wavenumbers between 6 and 12 and large amplitudes in the Australian region.

\section{Midlatitude Onset-of-Blocking Modes}

5.1. Growth Rates and Periods. For the time intervals 1949 68, 1975-94, and 1997-2006, the leading southern hemisphere midlatitude onset-of-blocking modes $[23,30]$ are modes 30, 21, and 26 as shown in Tables 1 and 2. All have periods of 6 days but growth rates of 0.257 day $^{-1}$, 0.228 day $^{-1}$, and 0.207 day $^{-1}$ and pattern correlations with mode 30 for $1949-68$ of 1.0, 0.460 , and 0.640 , respectively. Thus there are reductions in growth rates of 11.2 per cent and 19.2 per cent in 1975-94 and 1997-2006 compared with 1949-68.

5.2. Structures of Midlatitude Onset-of-Blocking Modes. Midlatitude dipole onset-of-blocking modes are eastward propagating, have longer periods than cyclogenesis modes (approximately 6 days in Tables 1 and 2), are of somewhat larger scale, and have dipole structures in the latitudinal direction in the major regions of observed Southern Hemisphere blocking. Figure 5 shows an example of a mid-latitude onset-of-blocking mode (mode 26) for the 1997-2006 basic state; the depicted upper-level streamfunction has dipole structures between Australia and New Zealand, extending downstream over the central Pacific Ocean and there are dipole structures over the southern Atlantic Ocean as well.
We note from Tables 1 and 2 that there are somewhat similar onset-of-blocking modes for the periods 1949-68 and 197594 but that the different basic states cause changes in the structures since the pattern correlations are at best moderate. The primary differences in structures in the midlatitude onset-of-blocking modes for the three periods relate to differences in the longitude of maximum amplitude of upper-level RPEA streamfunction (not shown) near 30S. For mode 26 for the 1997-2006 basic state, this maximum occurs near 120W; for mode 21 for the 1975-94 basic state, it occurs near 135W; and for mode 30 for the 1949-68 basic state it occurs near $170 \mathrm{~W}$ with relatively larger amplitude blocks in the region of New Zealand. We also note that the growth rates in 1997-2006 and 1975-94 are approximately 19\% and approximately $11 \%$ less than for 1949-68, respectively. We expect that the growth rate reductions in 1975-94 and 1997-2006 compared with 1949-68 at least partly reflect the reductions in baroclinicity of the subtropical jet that cause even greater reductions in the growth rate of storm track modes. The blocking highs in the region of New Zealand are also frequently associated with rain-bearing east coast lows on the east coast of Australia. Again, the changes and trends in rainfall over Australia in Figure 1 show reductions and negative trends in rainfall along the east coast of Australia consistent with the smaller average growth rates of these larger-scale modes since the 1970s.

\section{Northwest Cloud-Band Modes}

6.1. Growth Rates and Periods. In Figure 1 we also see that there are regions of increased rainfall stretching southeast from northwest and central Western Australia. These are regions often affected by propagating cloud-bands originating off the northwest coast of Australia. Here we examine the extent to which these results may be related to changes in northwest cloud-band (NWCB) disturbances [41]. The leading northwest cloud band modes for the time intervals 1949-68, 1975-94, and 1997-2006 are modes 43, 12, and 7, and all have periods of 8 days but growth rates of 0.210 day $^{-1}$, $0.262 \mathrm{day}^{-1}$, and $0.305 \mathrm{day}^{-1}$ and pattern correlations with mode 43 for $1949-68$ of 1.0, 0.840, and 0.637, respectively. 
This corresponds to increases in growth rates of 24.9 per cent and 45.4 per cent during 1975-94 and 1997-2006, respectively.

6.2. Structures of Northwest Cloud-Band Modes. The northwest cloud-band modes in Tables 1 and 2 are eastward propagating with periods of approximately 8 days although there are also slower-growing NWCB modes with longer periods (as discussed in a different context by C. S. Fredriksen and J. S. Fredriksen [41]). Mode 12 for the 1975-94 basic state is a NWCB mode that emanates from the region of the Indian Ocean, crosses Australia, and then propagates into the central Pacific and south across South America. It again is of larger scale than the storm track modes such as that shown in Figure 4. It also differs significantly from the storm track and onset-of-blocking modes in that its growth rate is approximately $25 \%$ greater than the corresponding mode for $1949-68$. This increases to approximately $45 \%$ for NWCB mode 7 for the 1997-2006 basic state compared to the corresponding NWCB mode for the 1949-68 basic state.

Figure 6 shows some of the features of mode 12 for the 1975-94 basic state. The upper-level disturbance streamfunction is shown in Figure 6(a) with a characteristic wave train emanating from the Indian Ocean off the northwest coast. The RPEA of this field for this mode is shown in Figure 6(b) and illustrates the large impact (i.e., maxima in amplitude) of the mode over the Indian Ocean and central Australia. The upper-level divergence field depicted in Figure 6(c) shows large amplitude over central Western Australia and northern Queensland, where it would be expected to have a large impact on the rainfall. The fact that the growth rate continues to increase compared with the earliest period is consistent with the increased tendency for these modes to develop and consequently for the increase in rainfall shown over northwest Western Australia and northern Queensland (Figure 1).

\section{Intraseasonal Oscillation Modes}

7.1. Growth Rates and Periods. Next, we consider the leading intraseasonal oscillation modes $[29,31]$ for the time intervals 1949-68, 1975-94, and 1997-2006. As seen from Tables 1 and 2, they are modes 57, 35, and 33 and have periods of 59 days, 35 days, and 25 days, growth rates of $\left(0.144\right.$ day $^{-1}$, 0.186 day $^{-1}, 0.189$ day $^{-1}$ ) and pattern correlations with mode 57 for $1949-68$ of $(1.0,0.851,0.574)$ respectively. This corresponds to increases in growth rates of $28.7 \%$ and $30.6 \%$ during 1975-94 and 1997-2006, respectively.

7.2. Structures of Intraseasonal Modes. The July intraseasonal oscillation modes for basic states during the second half of the twentieth century have streamfunctions that extend from the equator into both hemispheres. In the Southern Hemisphere, eastward propagating mode 35 for the 1975-94 basic state has a wave train extending from the Indian Ocean across Australia into the central and south Pacific as shown in Figure 7(a) for the $300 \mathrm{hPa}$ disturbance streamfunction. The $300 \mathrm{hPa}$ divergence field at the phase depicted in Figure 7(b) has large amplitude over central Western Australia. It is interesting to note how the period and growth rate of this mode change between the time intervals 1949-68, 1975-94, and 1997-2006. We see from Tables 1 and 2 that the periods of this intraseasonal oscillation mode are reduced from 57 days to 42 days to 25 days. At the same time the growth rate increases by approximately $29 \%$ between $1949-68$ and $1975-$ 94 and by approximately $31 \%$ between $1949-68$ and 19972006. We also note that while the correlation between mode 33 for $1997-2006$ and mode 57 for $1949-68$ is 0.5744 , it is considerably larger with mode 35 for 1975-94 at 0.8030 (not shown). Thus there is a systematic change in the properties of the intraseasonal oscillation modes with time.

The $300 \mathrm{hPa}$ divergence field depicted in Figure 7(b) has large amplitude over central Western Australia, much like the NWCB mode (Figure 6(c)). Again, the increase in the growth rate of this mode is consistent with the increased development of these systems and hence the increase in rainfall over this part of Western Australia.

\section{Other Dynamically Important Weather Modes}

There are groups of other leading modes that also could potentially play important roles in the changing climate during the second half of the 20th century. These include high-latitude blocking modes, Antarctic modes, and African easterly waves.

8.1. High-Latitude Blocking Modes. High-latitude blocking modes, such as modes 4 and 6 for 1975-94, have significant amplitudes at high latitudes between New Zealand and Antarctica, as well as in midlatitudes; they have tripole structures in latitude at some longitudes (not shown). In mid-latitudes there are dipole structures downstream of Australia with additional centres around Antarctica similar to those for the mode shown in Figure 7 of J. S. Frederiksen and C. S. Frederiksen [30]. For the three time intervals considered throughout this paper, these modes have periods between 5 and 8 days (Tables 1 and 2) and are eastward propagating but show little systematic change in growth rates. Perhaps this is because they also grow on both the polar jet that has strengthened and on the subtropical jet that has weakened with time.

8.2. Antarctic Modes. For the 1975-94 basic state the two leading Antarctic modes are mode 3 with a period of approximately 17 days and mode 11 with a period of approximately 52 days. These two lower frequency modes are located principally over the Antarctic regions and consist of superpositions of zonal wavenumbers 2 and 3. They have close similarities with corresponding Antarctic teleconnection pattern modes of Frederiksen and Frederiksen [30, Figure 11]. Again, there are closely similar teleconnection pattern modes with the basic states for 1949-68 and for 1997-2006. These teleconnection patterns are little changed in growth rate or structure during the three periods of interest. This indicates that while there has been a change in the strength of the mean Antarctic oscillation (Section 2), its variability about the mean has changed less. 


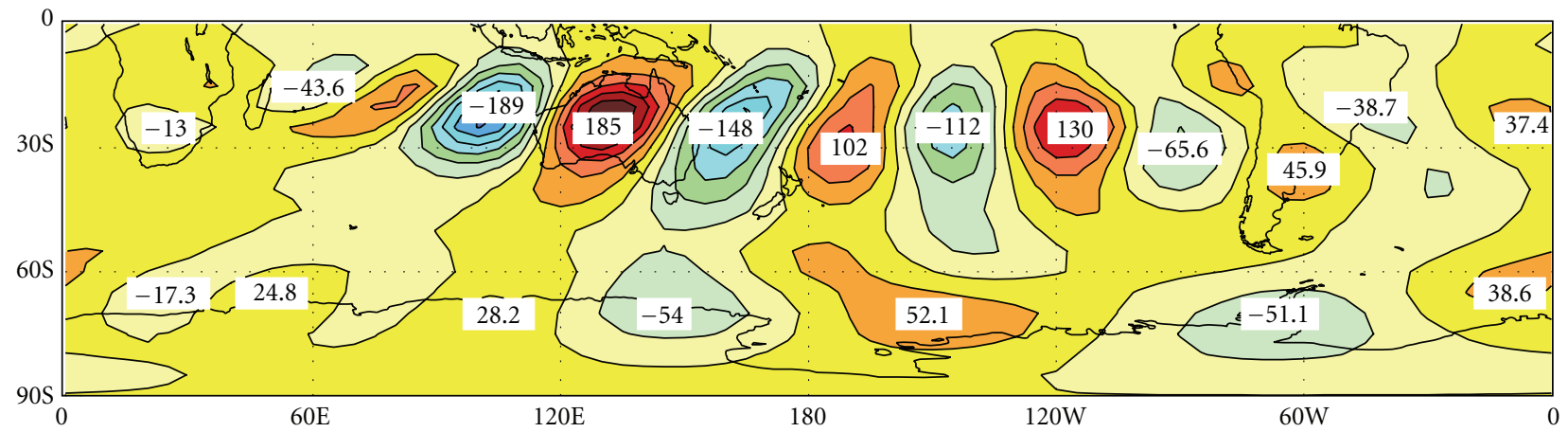

(a)

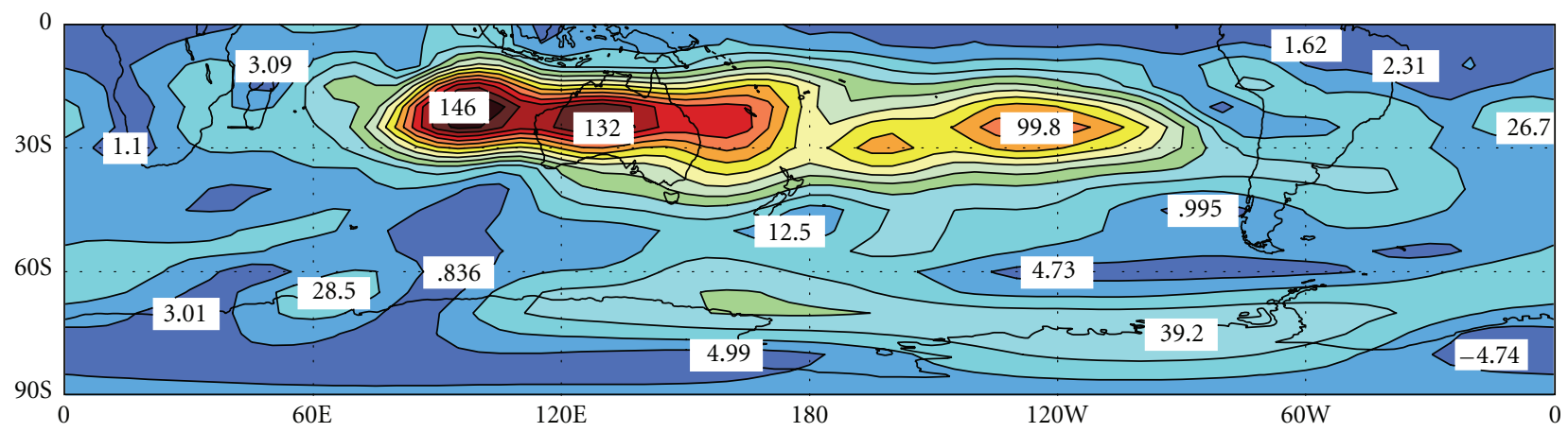

(b)

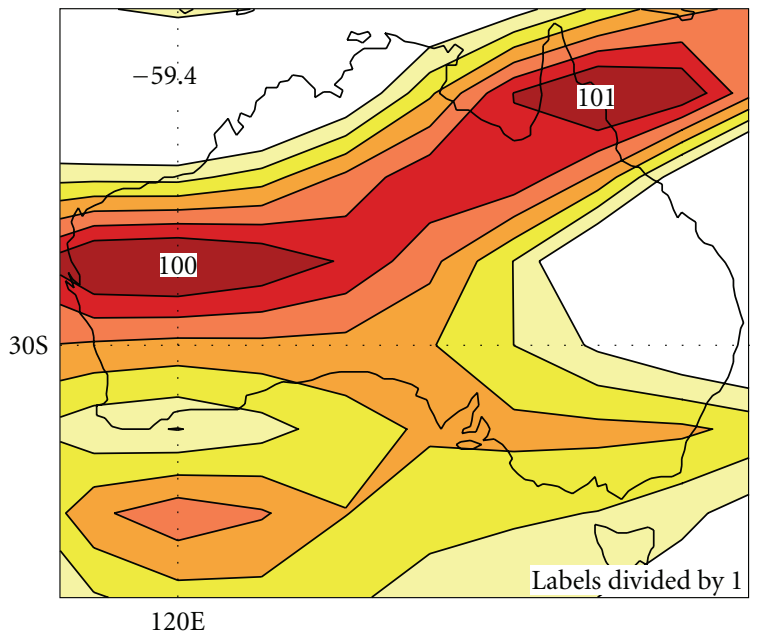

(c)

FIGURE 6: As in Figure 4 but for the SH upper-level streamfunction (a), the RPEA of the upper-level streamfunction (b), and the upper-level divergence in the Australian region (c) for the leading NWCB mode, mode 12, for the July 1975-94 basic state.

8.3. African Easterly Waves. African easterly waves are westward-propagating tropical waves that are generated by the African easterly jet and originate on the east coast of North Africa. They are frequent precursors of Atlantic hurricanes with about $85 \%$ of intense hurricanes having their origins as African easterly waves ([42] and references therein). The upper-level streamfunction for mode 7 for the 1975-94 basic state is shown in Figure 8. It is a baroclinic mode with a period of 4 days and with growth rates that are between 5\% and 7\% larger after 1975 than for the earlier period of 1949-68 (Tables 1 and 2).

\section{Sensitivity Studies}

In this study a rhomboidal $R=15$ truncation is used for both the perturbation and basic-state fields. This resolution, corresponding to $(3 R+1)$ by $(5 R+1) / 2$ grid points, or circa $750 \mathrm{~km}$ by $500 \mathrm{~km}$ at $30 \mathrm{~S}$ in longitude by latitude, has been used in many simulation and instability studies and is adequate for resolving the leading storm track modes and lower-frequency modes of variability. For example, the storm track in Figure 4(b), associated with the smallest scale wavenumber 12 mode considered here, has a longitudinal 


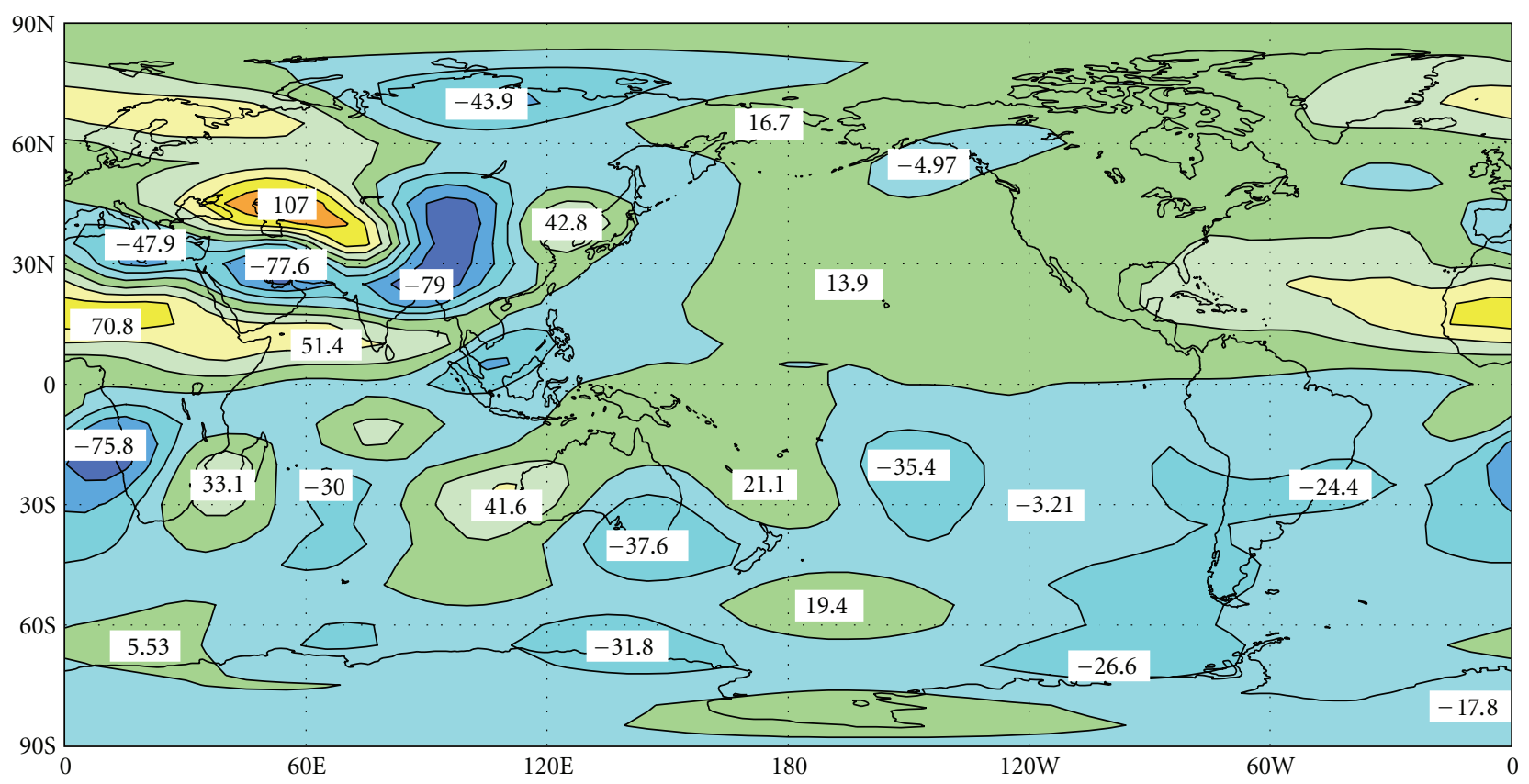

(a)

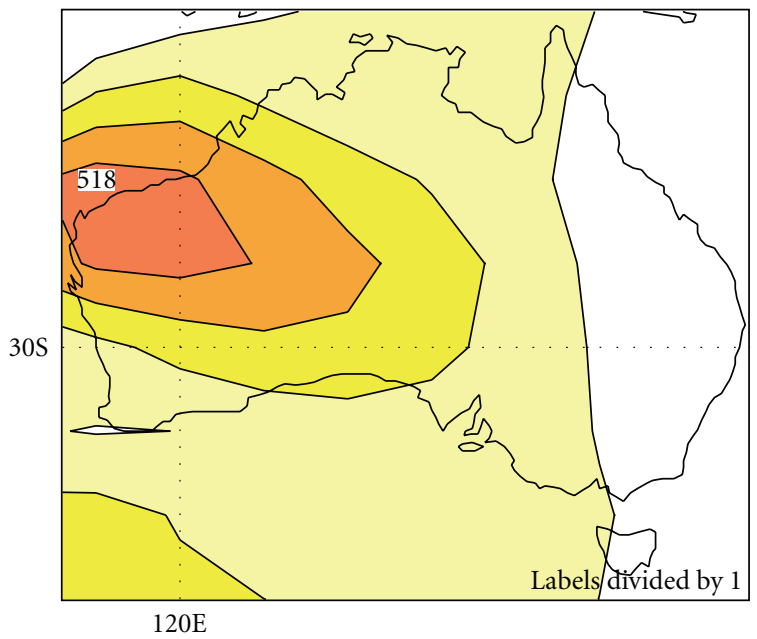

(b)

FIGURE 7: As in Figure 4 but for the global upper-level streamfunction (a) and the upper-level divergence in the Australian region (b) for the leading intraseasonal oscillation mode, mode 35, for the July 1975-94 basic state.

extent of around $4000 \mathrm{~km}$ and a latitudinal extent of circa $2000 \mathrm{~km}$ in the Australian region. Studies of the relationship between resolution and the dissipation required to obtain the same large-scale mean and transient flow properties and predictability have been carried out by Frederiksen and Kepert [43] and Zidikheri and Frederiksen [44]. Here we examine the sensitivity of the instability properties for a range of dissipations to draw general conclusions.

Our standard dissipation $K^{\prime d}=2.338 \times 10^{16} \mathrm{~m}^{4} \mathrm{~s}^{-1}$ has also been the standard dissipation used in many general circulation models at rhomboidal $R=15$ resolution going back to the 1970s ([25] and references therein). We expect that this is the most realistic choice, but in this section we also present results for mid-latitude blocking, northwest cloud band and intraseasonal oscillation modes for twice this value and with zero dissipation to gauge the sensitivity of our results. Tables 3 and 4 show the mode number, period $T_{r}^{d}$, growth rate $\omega_{i}^{d}$, and e-folding time $\tau_{i}^{d}$ of these modes with twice and zero dissipation and the largest pattern correlations $A_{c}$ with the corresponding mode with standard dissipation for the 1949-68 and 1975-94 basic states, respectively. Table 5 shows the change in the growth rate $\Delta \omega_{i}^{d}$ for these modes between 1949-68 and 1975-94 and how it depends on the strength of the dissipation.

We see from Table 5 that the changes in $\Delta \omega_{i}^{d}$ are generally quite similar for standard and zero dissipation and thus 


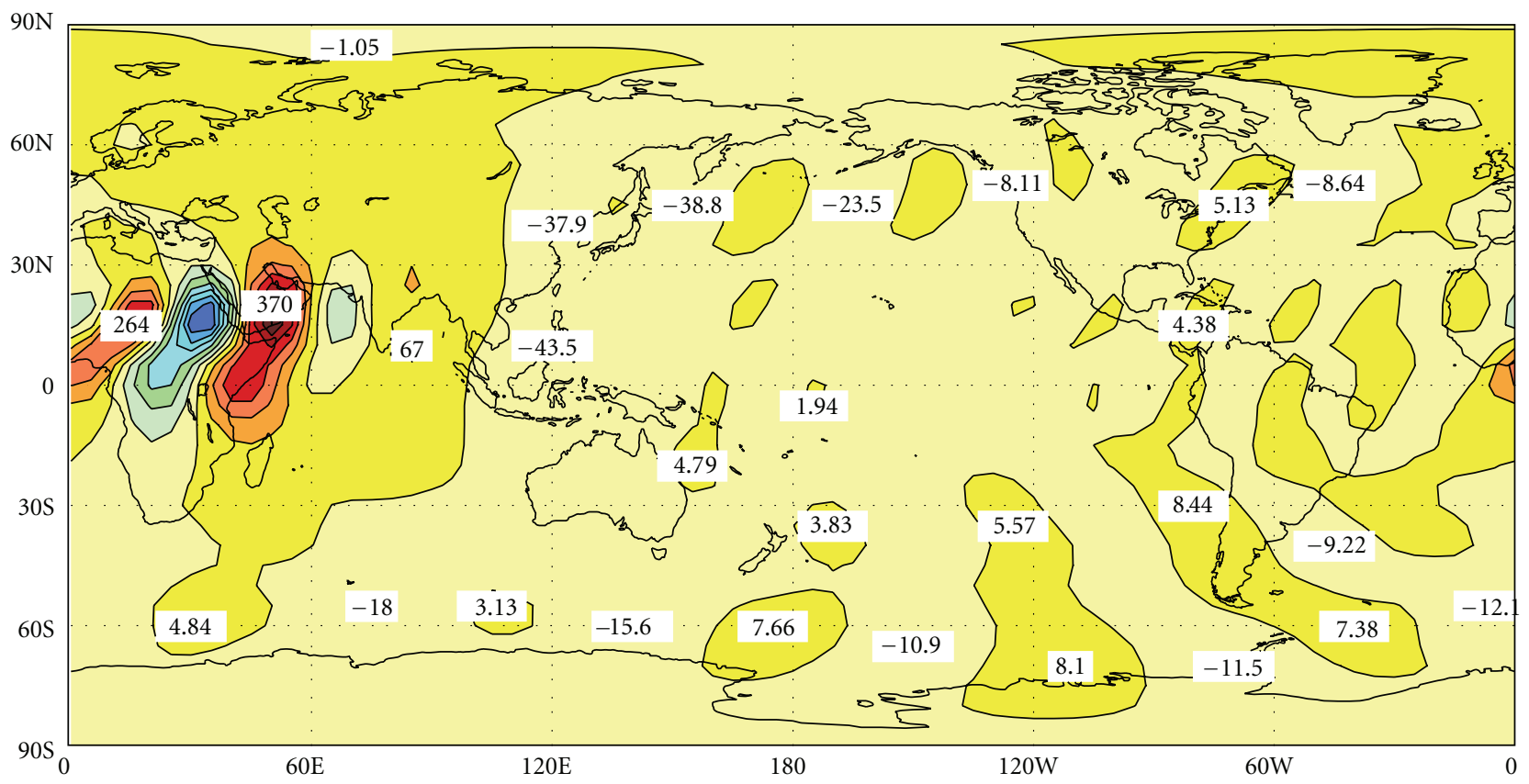

FIgURe 8: As in Figure 4(a) but for the African easterly wave, mode 7, for the July 1975-94 basic state.

TABLe 3: Periods $T_{r}^{d}$, growth rates $\omega_{i}^{d}$, and e-folding times $\tau_{i}^{d}$, of modes for the $1949-68$ basic state with $Q_{F}^{d}=1500 \mathrm{~K}^{2}$ and $C_{F}^{d}=5 \times 10^{-4} \mathrm{~K} \mathrm{~m}^{-1}$ and for different $K^{\prime d}$, which have the largest pattern correlations $A_{c}$ with leading ML blocking, NWCB, and ISO modes for the 1949-68 basic state with standard parameterizations. Also shown are the mode numbers.

\begin{tabular}{lccccccc}
\hline Class & Mode & $\begin{array}{c}K^{\prime d} \\
\mathrm{~m}^{4} \mathrm{~s}^{-1}\end{array}$ & $\begin{array}{c}T_{r}^{d} \\
(\text { days })\end{array}$ & $\begin{array}{c}\omega_{i}^{d} \\
\left(\text { day }^{-1}\right)\end{array}$ & $\begin{array}{c}\tau_{i}^{d} \\
\text { (days) }\end{array}$ & $\begin{array}{c}A_{c} \\
\text { Mode } \\
\text { standard }\end{array}$ \\
\hline ML blocking & 58 & 0 & 6.016 & 0.3069 & 3.258 & 0.7956 \\
ML blocking & 15 & $4.676 \times 10^{16}$ & 6.188 & 0.2214 & 4.517 & 0.9375 \\
NWCB & 40 & 0 & 9.833 & 0.3833 & 2.609 & 0.7412 & 30 \\
NWCB & 45 & $4.676 \times 10^{16}$ & 8.800 & 0.1096 & 9.126 & 0.7049 & 43 \\
ISO & 95 & 0 & 53.88 & 0.1777 & 5.628 & 0.8375 \\
ISO & 56 & $4.676 \times 10^{16}$ & 61.41 & 0.0868 & 11.52 & 0.9155 & 57 \\
\hline
\end{tabular}

that the results should depend only weakly on dissipation in this range. For twice the dissipation, the differences in $\Delta \omega_{i}^{d}$ increase for NWCB and ISO modes that are close to the instability threshold while $\Delta \omega_{i}^{d}$ is more similar to that for the standard dissipation for the mid-latitude blocking modes that are further from threshold. This is to be expected. For all our choices of dissipation, the changes in growth rate $\Delta \omega_{i}^{d}$ for mid-latitude blocking, northwest cloud band, and intraseasonal oscillation modes between 1949-68 and 197594 are significant.

\section{Discussion and Conclusions}

In this paper, we have sought to understand some of the changes and trends in Australian winter rainfall over the last fifty or so years in the context of changes in the SH largescale circulation and the associated properties of relevant $\mathrm{SH}$ weather systems and modes of variability. We have examined, in particular, the changes in the structures and growth rates of the leading $\mathrm{SH}$ instability modes derived from an atmospheric primitive equation model. Decreased, or increased growth rates are generally an indication of whether the particular mode is less or more likely to develop into mature systems and impact on the rainfall.

We have conducted this study with July climatological basic states averaged over the periods 1949-1968, 19751994, and 1997-2006. As in J. S. Frederiksen and C. S. Frederiksen $[1,2]$ we find that the largest decreases in growth rates occur for the cyclogenesis, or storm track, modes with reductions of 33\% and 37\% during 1975-1994 and 1997-2006, respectively, compared to 1949-1968. These modes were shown to have largest impact on rainfall over southwestern Australia and southern Australia in general. The reduction in growth rate of these storm track modes implies a reduced tendency for their development and would explain the reduced rainfall and negative rainfall trends over much of southern Australia.

Our analysis has also shown a significant decrease in the growth rate of modes associated with the onset of midlatitude blocking. For these modes we have found reductions 
TABle 4: As in Table 3 for modes for 1975-94 basic states with different dissipation parameterizations, $K^{\prime d}$, that have the largest pattern correlations, $A_{c}$, with leading ML blocking, NWCB, and ISO modes for the 1975-94 basic state with standard parameterizations.

\begin{tabular}{lccccccc}
\hline Class & Mode & $\begin{array}{c}K^{\prime d} \\
\mathrm{~m}^{4} \mathrm{~s}^{-1}\end{array}$ & $\begin{array}{c}T_{r}^{d} \\
(\text { days })\end{array}$ & $\begin{array}{c}\omega_{i}^{d} \\
(\text { day }\end{array}$ & $\begin{array}{c}\left.\tau_{i}^{d}\right) \\
\text { (days) }\end{array}$ & $\begin{array}{c}A_{c} \\
\text { Standard }\end{array}$ \\
\hline ML blocking & 55 & 0 & 6.205 & 0.2831 & 3.532 & 0.7707 & 21 \\
ML blocking & 11 & $4.676 \times 10^{16}$ & 6.218 & 0.1862 & 5.371 & 0.8237 \\
NWCB & 6 & 0 & 8.806 & 0.4894 & 2.043 & 0.6338 & 12 \\
NWCB & 19 & $4.676 \times 10^{16}$ & 7.514 & 0.1579 & 6.334 & 0.7850 & 12 \\
ISO & 75 & 0 & 34.37 & 0.2294 & 4.358 & 0.8654 & 35 \\
ISO & 22 & $4.676 \times 10^{16}$ & 43.28 & 0.1492 & 6.701 & 0.9584 \\
\hline
\end{tabular}

TABLE 5: Changes in growth rates, $\Delta \omega_{i}^{d}$, for leading blocking, NWCB, and ISO modes when basic state is changed from 1949-68 basic state to 1975-94 basic, for different dissipation parameters, $K^{\prime d}$.

\begin{tabular}{lcccc}
\hline$K^{\prime d}$ & Basic state & Mode & Basic state & \multicolumn{1}{c}{$\Delta \omega_{i}^{d}$} \\
$\mathrm{~m}^{4} \mathrm{~s}^{-1}$ & $1949-68$ & 30 ML blocking & $1975-94$ & 21 ML blocking \\
\hline $2.338 \times 10^{16}$ & $1949-68$ & 15 ML blocking & $1975-94$ & 11 ML blocking \\
0 & $1949-68$ & 58 ML blocking & $1975-94$ & 55 ML blocking \\
$4.676 \times 10^{16}$ & $1949-68$ & 43 NWCB & $1975-94$ & 12 NWCB \\
$2.338 \times 10^{16}$ & $1949-68$ & 40 NWCB & $1975-94$ & 6 NWCB \\
0 & $1949-68$ & 45 NWCB & $1975-94$ & 19 NWCB \\
$4.676 \times 10^{16}$ & $1949-68$ & 57 ISO & $1975-94$ & $+24.9 \%$ \\
$2.338 \times 10^{16}$ & $1949-68$ & 95 ISO & $1975-94$ & $+27.7 \%$ \\
0 & $1949-68$ & 56 ISO & $1975-94$ & $+44.1 \%$ \\
$4.676 \times 10^{16}$ & & & & +22 ISO \\
\hline
\end{tabular}

in growth rate of $11 \%$ and $19 \%$ in 1975-1994 and 19972006, respectively, compared with the earliest period. The structures of these modes, at appropriate phases, show a blocking high over New Zealand and a low pressure cell off the eastern seaboard of Australia. This low pressure cell is conducive to the development of rain bearing east coast lows on the east coast of Australia. This region has experienced quite large reductions in rainfall over many decades consistent with the reduced growth rate of these modes and hence the reduced tendency for the development of east coast lows.

Not all of Australia has experienced reductions in winter rainfall. Over the central northwest of Western Australia, central eastern Australia, and northern Queensland, there have been increases and positive trends in rainfall. Our study suggests that these positive changes are attributable to the changing nature of two types of weather systems commonly associated with these regions. The first of these is associated with eastward-propagating northwest cloud-bands originating in the Indian Ocean off northwest Australia. Over the last fifty or so years, these NWCB modes have increased their growth rates by around $25 \%$ and $45 \%$, respectively, for the 1975-1994 and 1997-2006 basic states compared with 19491968. The increasing likelihood of the development of these systems would have a positive impact over the three regions mentioned above and can partly explain the observational changes.

Another category of mode that has an impact on rainfall over the central northwest of Western Australia is associated with variability at the intraseasonal timescale. For these modes we see an increase in growth rate of around 29\% and 31\% for 1975-1994 and 1997-2006 compared to 1949-1968. However, we have also noticed a continual decrease in the period of these modes from 59 days to 35 days and finally 25 days in the last period. Again, the increased growth rate of these modes is consistent with the increased rainfall trends over central northwestern Western Australia.

Other modes that show some significant change in their growth rate are those associated with African easterly waves, which are westward-propagating tropical waves generated by the African easterly jet and originating off the east coast of North Africa. These have increased growth rates of 5\% and 7\% in the latter two periods compared with 1949-1968. However, these have no relevance for Australian rainfall. The other modes, such as high-latitude blocking modes and Antarctic modes, do not show any significant changes in their growth rates or horizontal structure.

In subsequent papers, we plan to analyze the changing properties of $\mathrm{SH}$ atmospheric modes in other seasons to try to better understand the observed changes in rainfall and climate, in general.

\section{Appendix}

A.

A.1. Primitive Equation Instability Model. The synoptic weather modes described in this paper have been derived using the two-level linearized primitive equation model 
described in more detail in J. S. Frederiksen and C. S. Frederiksen [2]. The model includes a generalized Kuo-type heating parameterization that incorporates closures for both convection and evaporation-wind feedback formulated in more detail in their appendix. Briefly, the linearized primitive equations are described in terms of a mean perturbation streamfunction $\psi$, which is the average between the values at the upper (level 1) and lower (level 3) levels, a vertical shear perturbation streamfunction $\tau$, which is half the difference between the upper and lower-level values, the lower-level perturbation velocity potential $\chi$ (equal to minus the upperlevel velocity potential), and the mean and vertical shear perturbation potential temperatures $\theta$ and $\sigma$, respectively.

The linearized primitive equations are as follows:

$$
\begin{aligned}
\frac{\partial \nabla^{2} \psi}{\partial t}= & -J\left(\bar{\psi}, \nabla^{2} \psi\right)-J\left(\psi, \nabla^{2} \bar{\psi}+2 \mu+\frac{1}{2} h\right) \\
& -J\left(\bar{\tau}, \nabla^{2} \tau\right)-J\left(\tau, \nabla^{2} \bar{\tau}-\frac{1}{2} h\right) \\
& +J\left(\bar{\chi}, \nabla^{2} \chi\right)+J\left(\chi, \nabla^{2} \bar{\chi}\right) \\
& +\nabla \cdot\left(\left(\nabla^{2} \bar{\tau}-\frac{1}{2} h\right) \nabla \chi\right)+\nabla \cdot\left(\nabla^{2} \tau \nabla \bar{\chi}\right) \\
& +\nabla \cdot\left(\nabla^{2} \bar{\chi} \nabla \tau\right)+\nabla \cdot\left(\nabla^{2} \chi \nabla \bar{\tau}\right) \\
& -K \nabla^{2}(\psi-\tau)-K^{\prime} \nabla^{6} \psi,
\end{aligned}
$$

$$
\begin{aligned}
\frac{\partial \nabla^{2} \tau}{\partial t}= & -J\left(\bar{\psi}, \nabla^{2} \tau\right)-J\left(\psi, \nabla^{2} \bar{\tau}-\frac{1}{2} h\right) \\
& -J\left(\bar{\tau}, \nabla^{2} \psi\right)-J\left(\tau, \nabla^{2} \bar{\psi}+2 \mu+\frac{1}{2} h\right) \\
& +\nabla \cdot\left(\left(\nabla^{2} \bar{\psi}+2 \mu+\frac{1}{2} h\right) \nabla \chi\right)+\nabla \cdot\left(\nabla^{2} \psi \nabla \bar{\chi}\right) \\
& +K \nabla^{2}(\psi-\tau)-K^{\prime} \nabla^{6} \tau
\end{aligned}
$$

$$
\begin{aligned}
\frac{\partial \nabla^{2} \chi}{\partial t}= & -J\left(\bar{\chi}, \nabla^{2} \psi\right)-J\left(\chi, \nabla^{2} \bar{\psi}+2 \mu+\frac{1}{2} h\right) \\
& -\nabla \cdot\left(\left(\nabla^{2} \bar{\psi}+2 \mu+\frac{1}{2} h\right) \nabla \tau\right)-\nabla \cdot\left(\nabla^{2} \psi \nabla \tau\right) \\
& -\nabla \cdot\left(\left(\nabla^{2} \bar{\tau}-\frac{1}{2} h\right) \nabla \psi\right)-\nabla \cdot\left(\nabla^{2} \psi \nabla \bar{\tau}\right) \\
& +\nabla^{2}(\nabla \bar{\psi} \cdot \nabla \tau+\nabla \psi \cdot \nabla \bar{\tau} \\
& -J(\bar{\psi}, \chi)-J(\psi, \bar{\chi})+\theta) \\
& -K \nabla^{2} \chi-K^{\prime} \nabla^{6} \chi
\end{aligned}
$$

$$
\begin{aligned}
\frac{\partial \theta}{\partial t}= & -J(\bar{\psi}, \theta)-J(\psi, \bar{\theta})-J(\bar{\tau}, \sigma)-J(\tau, \bar{\sigma}) \\
& +\nabla \cdot \bar{\sigma} \nabla \chi+\nabla \cdot \sigma \nabla \bar{\chi}-K^{\prime} \nabla^{4} \theta \\
& -\bar{s} \nabla^{2} \chi+C_{F}\left(u^{(3)} f_{u}+v^{(3)} f_{v}\right), \\
\frac{\partial \sigma}{\partial t}= & -J(\bar{\psi}, \sigma)-J(\psi, \bar{\sigma})-J(\bar{\tau}, \theta)-J(\tau, \bar{\theta}) \\
& +\nabla \cdot \bar{\theta} \nabla \chi+\nabla \cdot \theta \nabla \bar{\chi}-K^{\prime} \nabla^{4} \sigma .
\end{aligned}
$$

The fields with an overbar refer to the basic state, the Jacobian

$$
J(X, Y)=\frac{\partial X}{\partial \lambda} \frac{\partial Y}{\partial \mu}-\frac{\partial X}{\partial \mu} \frac{\partial Y}{\partial \lambda},
$$

and $\lambda$ is longitude, $\mu$ is sine of latitude $\phi$, and $t$ is time. The strength of the diffusion is specified by $K$ and $K^{\prime}$ which denote surface drag and biharmonic diffusion coefficients, respectively. Also $h=2 \mu \mathrm{g} A H /\left(R T_{0}\right)$ where $H$ is the global topography as shown in Figure 1(d) of J. S. Frederiksen and C. S. Frederiksen [29], $g$ is the gravitational acceleration, $R$ is the gas constant for air, $T_{0}$ is the horizontally averaged surface temperature, and $A$ is a vertical profile factor taken to be 1 . These equations have been nondimensionalized by using $a$, the radius of the earth, as a length scale; $\Omega^{-1}$, the inverse of the earth's angular speed of rotation, as a time scale; and $a^{2} \Omega^{2} / b_{\kappa} c_{p}$ as a temperature scale, where $c_{p}$ is the specific heat at constant pressure and $b_{\kappa}=0.124$ is a dimensionless constant. Corresponding dimensional quantities are indicated by the superscript $d$ in the sequel.

A heating profile, for which the generalized Kuo-type heating projects completely onto the internal mode dynamics, is used (see appendix of [2]). The heating due to convection and surface evaporation then only enters the linearized mean potential temperature equation (A.1d) and is given by

$$
\widetilde{Q}_{\theta}=-\bar{s} \nabla^{2} \chi+C_{F}\left(u^{(3)} f_{u}+v^{(3)} f_{v}\right),
$$

where the basic-state moisture destabilization parameter is

$$
\bar{s}=\frac{A_{F} m L \bar{q}}{c_{p}}=Q_{F} \bar{q},
$$

and the evaporation structure functions are

$$
\begin{aligned}
& f_{u}=\frac{\left(\bar{q}_{s}-\bar{q}\right) \bar{u}^{(3)}}{\left[\left(\bar{u}^{(3)}\right)^{2}+\left(\bar{v}^{(3)}\right)^{2}\right]^{1 / 2}}, \\
& f_{v}=\frac{\left(\bar{q}_{s}-\bar{q}\right) \bar{v}^{(3)}}{\left[\left(\bar{u}^{(3)}\right)^{2}+\left(\bar{v}^{(3)}\right)^{2}\right]^{1 / 2}} .
\end{aligned}
$$

Here, $u^{(3)}\left(\bar{u}^{(3)}\right)$ and $v^{(3)}\left(\bar{v}^{(3)}\right)$ are the lower-level zonal and meridional perturbation (basic state) velocities; $\bar{q}$ and $\bar{q}_{s}$ 
are the basic state specific humidity and saturation specific humidity at the lower-level, respectively. We assume that $\bar{q}$ is essentially equivalent to the moisture mixing ratio $\bar{W}$. Further,

$$
\begin{gathered}
Q_{F}=\frac{2(1-b) A_{F} L}{c_{p}}=\frac{m A_{F} L}{c_{p}}, \\
C_{F}=\frac{C_{E} \rho\left(p_{1000}\right) g(1-b) A_{F} L}{\Delta p c_{p}} .
\end{gathered}
$$

Also, $m=2(1-b)$ is the moisture availability factor, where $(1-b)$ is the proportion of the total convergence of moisture, or "moisture accession", that is condensed and precipitated out as rain or carried away, and the fraction $b$ increases the humidity of the air in the Kuo [45] representation. More over,

$$
\begin{aligned}
A_{F} & =\left[\left(\frac{p_{750}}{p_{1000}}\right)^{\kappa}+\left(\frac{p_{500}}{p_{1000}}\right)^{\kappa}+\left(\frac{p_{250}}{p_{1000}}\right)^{\kappa}\right]^{-1} \\
& =0.414 .
\end{aligned}
$$

Here, $\kappa=R / c_{p}, c_{p}=1004 \mathrm{~J} \mathrm{~K}^{-1} \mathrm{~kg}^{-1}$ is the specific heat of air at constant pressure, $R=287 \mathrm{~K}^{-1} \mathrm{~kg}^{-1}$ is the gas constant for air, $L=2.5 \times 10^{6} \mathrm{~J} \mathrm{~kg}^{-1}$ is the latent heat of condensation, $g=9.8 \mathrm{~m} \mathrm{~s}^{-2}$ is the gravitational acceleration, $p_{1000}=1000 \mathrm{hPa}, p$ is pressure, the pressure spacing is $\Delta p=250 \mathrm{hPa}, C_{E}$ is a nondimensional drag coefficient, and $\rho\left(p_{1000}\right)=1.276 \mathrm{~kg} \mathrm{~m}^{-3}$ is the surface density of air.

The first term in (A.1c) is the convection parameterization which, in this linearized form, gives heating for rising motion and cooling for sinking motion. The second term in (A.1c) is the evaporation-wind feedback mechanism.

A.2. Standard Parameters. The synoptic weather modes experience the effects of the instability of the threedimensional basic-state fields and of convection, surface evaporation feedback, topography, and dissipation. The global topography is shown in Figure 1 (d) of J. S. Frederiksen and C. S. Frederiksen [29]. We use drag and biharmonic diffusion coefficients with values

$$
\begin{gathered}
K^{d}=8.39 \times 10^{-7} \mathrm{~s}^{-1}, \\
K^{\prime d}=2.338 \times 10^{16} \mathrm{~m}^{4} \mathrm{~s}^{-1}
\end{gathered}
$$

as in our previous studies.

The strength of the convective heating in (A.4) is specified by

$$
Q_{F}^{d}=1500 \mathrm{~K},
$$

and the corresponding moisture destabilization parameter $\bar{s}$ in (A.3) is positive. For a slowly varying basic-state static stability, we can combine the moisture destabilization parameter with the dry static stability term and define a moist static stability by

$$
\bar{\sigma}_{m}=\bar{\sigma}-\bar{s}
$$

The strength of the evaporation-wind feedback in (A.7) is specified by

$$
C_{F}^{d}=5 \times 10^{-4} \mathrm{Km}^{-1}
$$

A.3. Eigenvalue-Eigenvector Equations. Each of the perturbation fields and basic-state fields is expanded in terms of spherical harmonics with the perturbations also having a time dependence $\exp (-i \omega t)$. Here $t$ is the time and $\omega=$ $\omega_{r}+i \omega_{i}$ is the complex angular frequency with $\omega_{r}$ being the frequency and $\omega_{i}$ the growth rate. This then results in a system of eigenvalue-eigenvector equations of the form

$$
-i \omega \mathbf{x}=\mathbf{A x}
$$

where

$$
\mathbf{x}=\left(\ldots, \psi_{m n}, \ldots, \tau_{m n}, \ldots, \chi_{m n}, \ldots, \theta_{m n}, \ldots, \sigma_{m n}, \ldots\right)^{T} .
$$

is the column vector of spherical harmonic spectral coefficients of the five field variables, $T$ denotes transpose and the matrix A is determined as described in J. S. Frederiksen and C. S. Frederiksen [27]. In general, the eigenmodes together with their adjoint modes form a complete biorthogonal system for representing any disturbance [37]. A rhomboidal $R=15$ truncation is used for both the perturbation and basic-state fields in which the zonal wave number $m=$ $-15, \ldots, 0, \ldots, 15$ and the total wave number $n=|m|,|m|+$ $1, \ldots,|m|+15$. This resolution is adequate for resolving the leading synoptic weather modes and lower-frequency modes of variability.

\section{Acknowledgments}

It is a pleasure to thank Stacey Osbrough for assistance with this work. This work was partly funded by the Australian Government Department of Climate Change and Energy Efficiency and the Indian Ocean Climate Initiative of the W. A. Department of Environment, Water and Catchment Protection, and it contributes to the research effort of the CSIRO Climate Adaptation Flagship.

\section{References}

[1] J. S. Frederiksen and C. S. Frederiksen, "Decadal changes in Southern Hemisphere winter cyclogenesis," in CSIRO Marine and Atmospheric Research, p. 29, Aspendale, Victoria, Australia, 2005, http://www.cmar.csiro.au/e-print/open/frederiksenjs_2005b.pdf.

[2] J. S. Frederiksen and C. S. Frederiksen, "Interdecadal changes in southern hemisphere winter storm track modes," Tellus, vol. 59, no. 5, pp. 599-617, 2007.

[3] B. S. Sadler, G. W. Mauger, and R. A. Stokes, "The water resources implications of a drying climate in south-west Western Australia," in Greenhouse: Planning for Climate Change, G. I. Pearman, Ed., pp. 296-311, Commonwealth Scientific and Industrial Research Organisation, Australia, 1988.

[4] P. K. Hope, W. Drosdowsky, and N. Nicholls, "Shifts in the synoptic systems influencing southwest Western Australia," Climate Dynamics, vol. 26, no. 7-8, pp. 751-764, 2006. 
[5] N. Nicholls, Detecting, Understanding and Attributing Climate Change, Australian Greenhouse Office Publication, 2007.

[6] B. C. Bates, P. Hope, B. Ryan, I. Smith, and S. Charles, "Key findings from the Indian Ocean Climate Initiative and their impact on policy development in Australia," Climatic Change, vol. 89, no. 3-4, pp. 339-354, 2008.

[7] B. C. Bates, R. E. Chandler, S. P. Charles, and E. P. Campbell, "Assessment of apparent nonstationarity in time series of annual inflow, daily precipitation, and atmospheric circulation indices: a case study from southwest Western Australia," Water Resources Research, vol. 46, no. 12, Article ID W00H02, 2010.

[8] G. Ayers and Z. Levin, "Air pollution and precipitation," in Clouds in the Perturbed Climate System: Their Relationship to Energy balance, Atmospheric Dynamics, and Precipitation, J. Heintzenberg and R. J. Charlton, Eds., chapter 16, pp. 369399, MIT Press, Cambridge, UK, 2009.

[9] J. S. Frederiksen, C. S. Frederiksen, S. L. Osbrough, and J. M. Sisson, "Causes of changing Southern Hemisphere weather systems," in Managing Climate Change, I. Jubb, P. Holper, and W. Cai, Eds., chapter 8, pp. 85-98, CSIRO Publishing, Collingwood, Australia, 2010.

[10] C. S. Frederiksen, J. S. Frederiksen, J. M. Sisson, and S. L. Osbrough, "Changes and projections in Australian winter rainfall and circulation: anthropogenic forcing and internal variability," International Journal of Climate Change: Impacts and Responses, vol. 2, pp. 143-162, 2011.

[11] C. S. Frederiksen, J. S. Frederiksen, J. M. Sisson, and S. L. Osbrough, "Australian winter circulation and rainfall changes and projections," International Journal of Climate Change Strategies and Management, vol. 3, pp. 170-188, 2011.

[12] P. Hope and C. Ganter, "Recent and projected rainfall trends in south-west Australia and the associated shifts in weather systems," in Managing Climate Change, I. Jubb, P. Holper, and W. Cai, Eds., chapter 5, pp. 53-63, CSIRO Publishing, Collingwood, Australia, 2010.

[13] D. G. C Kirono. and D. M. Kent, "Assessment of rainfall and potential evaporation from global climate models and its implications for Australian regional drought projection," International Journal of Climatology, vol. 31, no. 9, pp. 1295$1308,2010$.

[14] T. D. van Ommen and V. Morgan, "Snowfall increase in coastal East Antarctica linked with southwest Western Australian drought," Nature Geoscience, vol. 3, no. 4, pp. 267-272, 2010.

[15] C. C. Urnmenhofer, C. Sen Gupta, M. J. Pook et al., "Anomalous rainfall over southwest Western Australia forced by Indian Ocean sea surface temperatures," Journal of Climate, vol. 21, pp. 5113-5134, 2008.

[16] C. C. Ummenhofer, C. Sen Gupta, A. S. Taschetto et al., "Modulation of Australian precipitation by meridional gradients in East Indian sea surface temperature," Journal of Climate, vol. 22, pp. 5597-5610, 2009.

[17] W. Cai and T. Cowan, "Dynamics of late autumn rainfall reduction over south-eastern Australia," Geophysical Research Letters, vol. 35, article L09708, no. 9, p. 5, 2008.

[18] B. F. Murphy and B. A. Timbal, "Review of recent climate variability and climate change in south-eastern Australia," International Journal of Climatology, vol. 28, no. 7, pp. 859879, 2008.

[19] J. S. Risbey, M. J. Pook, P. C. Mcintosh, C. C. Ummenhofer, and G. Meyers, "Characteristics and variability of synoptic features associated with cool season rainfall in southeastern Australia," International Journal of Climatology, vol. 29, no. 11, pp. 1595$1613,2009$.
[20] L. V. Alexander and S. Power, "Severe storms inferred from 150 years of sub-daily pressure observations along victoria's 'shipwreck coast," Australian Meteorological and Oceanographic Journal, vol. 58, no. 2, pp. 129-133, 2009.

[21] I. G. Watterson, "Relationships between south-eastern Australian rainfall and sea surface temperatures examined using a climate model," Journal Of Geophysical Research, vol. 115, article D10108, p. 14, 2010.

[22] J. S. Frederiksen, "Instability theory and predictability of atmospheric disturbances," in Frontiers in Turbulence and Coherent Structures, J. Denier and J. S. Frederiksen, Eds., chapter 2, pp. 29-58, World Scientific Lecture Notes in Complex Systems, 2007.

[23] J. S. Frederiksen, "The onset of blocking and cyclogenesis in Southern Hemisphere synoptic flows: linear theory," Journal of the Atmospheric Sciences, vol. 41, no. 7, pp. 1116-1131, 1984.

[24] J. S. Frederiksen, "Singular vectors, finite-time normal modes, and error growth during blocking," Journal of the Atmospheric Sciences, vol. 57, no. 2, pp. 312-333, 2000.

[25] J. S. Frederiksen, "Growth and vacillation cycles of disturbances in Southern Hemisphere flows," Journal of the Atmospheric Sciences, vol. 38, no. 7, pp. 1360-1375, 1981.

[26] N.A. Phillips, "Energy transformations and meridional circulations associated with simple baroclinic waves in a two-level, quasi-geostrophic model," Tellus, vol. 6, pp. 273-286, 1954.

[27] C. S. Frederiksen and J. S. Frederiksen, "Northern Hemisphere storm tracks and teleconnection patterns in primitive equation and quasi-geostrophic models," Journal of the Atmospheric Sciences, vol. 49, no. 16, pp. 1443-1458, 1992.

[28] D. A. Jones and G. Weymouth, "An Australian monthly rainfall data set," Tech. Rep. 70, p. 19, Bureau of Meteorology, Australia, 1997.

[29] J. S. Frederiksen and C. S. Frederiksen, "Monsoon disturbances, intraseasonal oscillations, teleconnection patterns, blocking, and storm tracks of the global atmosphere during January 1979: linear theory," Journal of the Atmospheric Sciences, vol. 50, no. 10, pp. 1349-1372, 1993.

[30] J. S. Frederiksen and C. S. Frederiksen, "Southern Hemisphere storm tracks, blocking, and low-frequency anomalies in a primitive equation model," Journal of the Atmospheric Sciences, vol. 50, no. 18, pp. 3148-3163, 1993.

[31] J. S. Frederiksen, "Genesis of intraseasonal oscillations and equatorial waves," Journal of the Atmospheric Sciences, vol. 59, no. 19, pp. 2761-2781, 2002.

[32] E. M. Kalnay, M. Kanamitsu, R. Kistler et al., "The NCEP/NCAR 40-year reanalysis project," Bulletin of the American Meteorological Society, vol. 77, no. 3, pp. 437-471, 1996.

[33] J. W. Kidson, "Interannual variations in the Southern Hemisphere circulation," Journal of Climate, vol. 1, pp. 1177-1198, 1988.

[34] J. C. Fyfe, "Extratropical Southern Hemisphere cyclones: harbingers of climate change?" Journal of Climate, vol. 16, no. 17, pp. 2802-2805, 2003.

[35] J. Brandefelt and E. Källén, "The response of the southern hemisphere atmospheric circulation to an enhanced greenhouse gas forcing," Journal of Climate, vol. 17, no. 22, pp. 4425-4442, 2004.

[36] G. J. Marshall, P. A. Stott, J. Turner, W. M. Turner, J. C. King, and T. A. Lachlan-Cope, "Causes of exceptional atmospheric circulation changes in the Southern Hemisphere," Geophysical Research Letters, vol. 31, no. 14, pp. L14205 1-4, 2004.

[37] J. S. Frederiksen and R. C. Bell, "North Atlantic blocking during January 1979: linear theory," Quarterly Journal of the 
Royal Meteorological Society, vol. 116, no. 496, pp. 1289-1313, 1990.

[38] J. S. Frederiksen, "The geographical locations of Southern Hemisphere storm tracks: linear theory," Journal of the Atmospheric Sciences, vol. 42, no. 7, pp. 710-723, 1985.

[39] I. Simmonds and K. Keay, "Variability of Southern Hemisphere extratropical cyclone behavior, 1958-97," Journal of Climate, vol. 13, no. 3, pp. 550-561, 2000.

[40] J. S. Frederiksen, "A unified three-dimensional instability theory of the onset of blocking and cyclogenesis," Journal of the Atmospheric Sciences, vol. 39, no. 5, pp. 969-987, 1982.

[41] C. S. Frederiksen and J. S. Frederiksen, "A theoretical model of Australian northwest cloudband disturbances and Southern Hemisphere storm tracks: the role of SST anomalies," Journal of the Atmospheric Sciences, vol. 53, no. 10, pp. 1410-1432, 1996.

[42] C. Thorncroft and K. Hodges, "African easterly wave variability and its relationship to Atlantic tropical cyclone activity," Journal of Climate, vol. 14, no. 6, pp. 1166-1179, 2001.

[43] J. S. Frederiksen and S. M. Kepert, "Dynamical subgrid-scale parameterizations from direct numerical simulations," Journal of the Atmospheric Sciences, vol. 63, no. 11, pp. 3006-3019, 2006.

[44] M. J. Zidikheri and J. S. Frederiksen, "Stochastic subgrid parameterizations for simulations of atmospheric baroclinic flows," Journal of the Atmospheric Sciences, vol. 66, no. 9, pp. 2844-2856, 2009.

[45] H. L. Kuo, "Further studies of the parameterization of the influence of cumulus convection on large scale flow," Journal of the Atmospheric Sciences, vol. 31, pp. 1232-1240, 1974. 

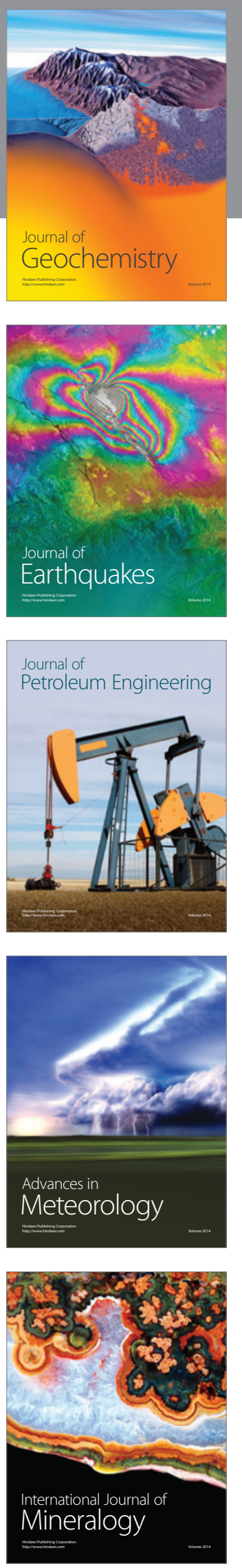
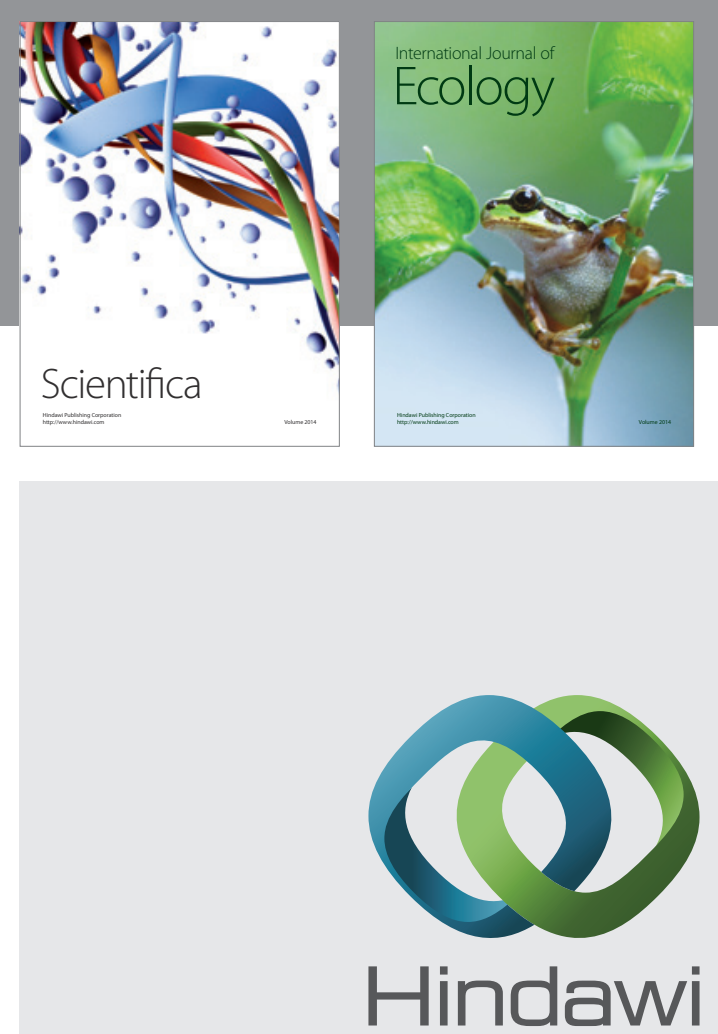

Submit your manuscripts at http://www.hindawi.com
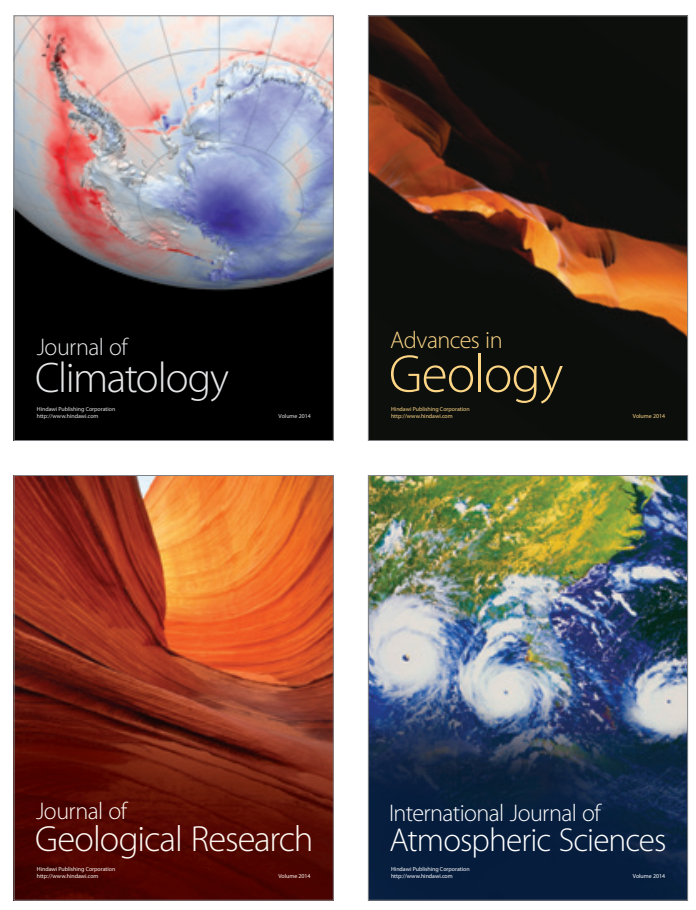
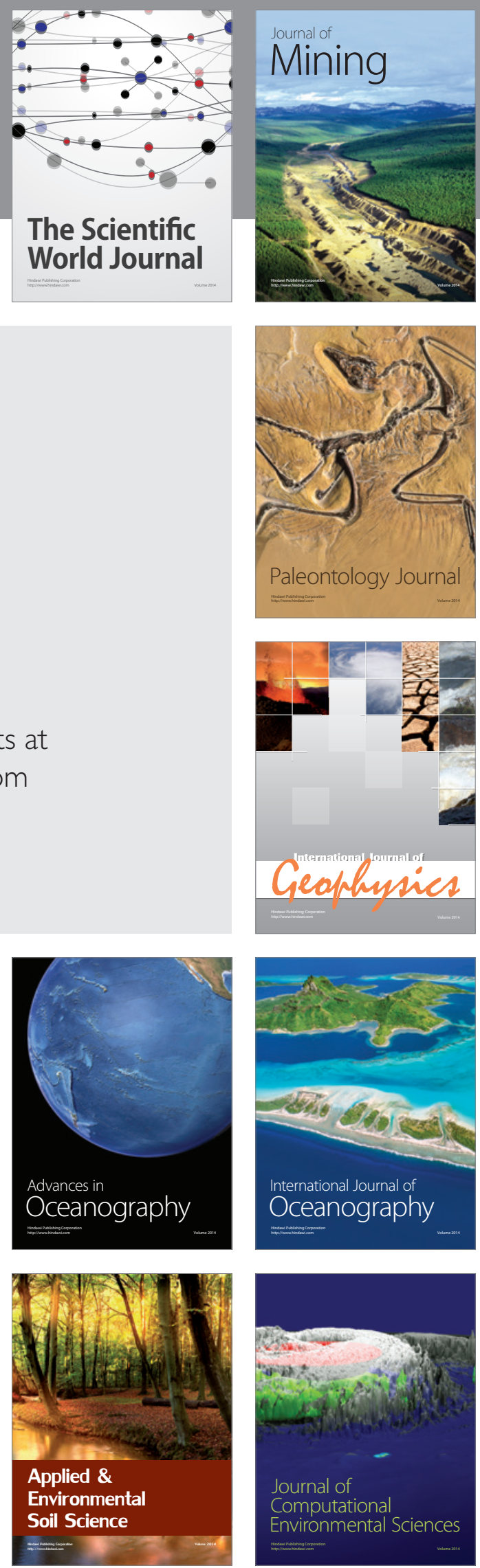